\title{
Pitch-Class Set Usage and Development in Late-Period Improvisations of John Coltrane
}

\author{
John O'Gallagher
}

\begin{abstract}
The recordings Stellar Regions and Interstellar Space, made by John Coltrane shortly before his death in 1967, are among his least studied and understood works. While these recordings are generally regarded as representative of 'free jazz', three case studies present evidence that Coltrane's improvisations on these recordings are highly organized, utilizing a structural methodology focused on trichordal pitch-class sets. Musical set theory is used as a primary analytical tool in combination with common jazz harmonic and improvisational practices. Analyses will illustrate the extensive use of $T_{n}$-types $(0,1,3)$ in "Iris", and $(0,2,4)$, and $(0,2,5)$ in "Saturn". As an exemplar of this methodology, compelling evidence in "Iris" demonstrates the use of $T_{n}$-type $(0,1,3)$, as a structural progenitor for both the saxophone improvisation and piano accompaniment for the entire length of the piece. En route, the potential influence of Nicolas Slonimsky's Thesaurus of Scales and Melodic Patterns (1947) is examined. As an archetype for an improvisational methodology focused on pitch-class sets, the significance of "Iris" resonates throughout Stellar Regions and Interstellar Space and more broadly to Coltrane's other late-period recordings, challenging the persistent characterization of this music as chaotic and "free".
\end{abstract}

\section{INTRODUCTION}

While there has been extensive research into John Coltrane's life and music, there are surprisingly few detailed inquires into the musical content of his late-period recordings Interstellar Space and Stellar Regions. ${ }^{1}$ This gap in our knowledge is generally the result of two factors: the music's extraordinary complexity that impedes its wider study, and the pervasive

\footnotetext{
${ }^{1}$ The critical use of "lateness" or late-period style when examining artistic works is a topic of wide debate that is explored in the collection of essays Late Style and Its Discontents: Essays in Art, Literature, and Music (McMullan and Smiles eds. 2016). I will use the term late-period as it is generally applied in Coltrane studies to address his recordings between 1965 and 1967. These include Stellar Regions and Interstellar Space.
} 
focus by researchers on the dominant Coltrane narratives (spiritual, political, historical). ${ }^{2}$ Those scholars who have analyzed Coltrane's late-period works have argued convincingly and overwhelmingly for its structural coherence - noting among other features, its motivic content. $^{3}$

This study presents wide-ranging evidence of an emergent structural device in Stellar Regions and Interstellar Space - one where motives are constructed from trichordal pitch-class sets (pc sets). The manner in which these sets occur, and more significantly, the pervasive and systematic use of $(0,1,3)$ - arguably for the first time in Coltrane's music - represents a distinctive development in Coltrane's work. Set theory is the principal methodology used in the analyses because it provides numerous tools for describing pc sets. ${ }^{4}$ This article uses Rahn's (1980) method for naming a pc set's "representative form" ( $T_{n}$-type)..$^{5}$ In accordance with Rahn's method, parentheses are used as an abbreviation for the enclosed representative forms when naming $T_{n}$-types (e.g., $\left.(0,1,3)=(0,1,3)_{T n}\right)$. This method is employed as an alternative to

\footnotetext{
${ }^{2}$ See for example Brown (2010), Cole (1976), Devito et al. (2013), Hall (2001, 113), Howison (2012), Kahn (2003), Kofsky (1998), Nisenson (1995), Ratliff (2008), Simpkins (1975), Smith (2001), Thomas (1976), Whyton (2013), and Woideck (1998).

${ }^{3}$ Jost (1974) is one of the first to argue for the structural coherence of Coltrane's late-period music. Several other scholars such as Block (1990), Liebman (2016), and McGill (2014) have argued similarly, often noting motivic content. Perhaps the best-known examination of Interstellar Space is by Porter $(1998,277)$. Porter first discusses the broader musical features of Interstellar Space and then follows with a focused analysis of "Venus." Voss (2015) has also written an insightful analysis of "Venus," expanding on and contrasting with Porter. An analysis of "Offering" by Pressing $(1982,153)$ is perhaps the earliest example of set theory being applied to the music of Coltrane. Pressing identifies $(0,2,7)$ and $(0,2,4)$ as the dominant structures in this piece. Schott $(2000,363)$ also examines the opening of "Offering," noting the presence of $(0,2,7)$ in support of Pressing's conclusions. This observation is echoed by Medwin (2008b, 81), noting a link between "Offering," the fanfare of "Acknowledgement" from A Love Supreme (1965), and the motivic content of "Evolution" from Live in Seattle (1965). Medwin uses the term "atomism" as a concept that encompasses Coltrane's motivic use, in a kind of expansion of Porter's "motivic cell" $(1998,234)$. In a parallel to the idea of pitch-class collections, Clements $(2008,161)$ suggests the Indian musical concept of vikriti as a possible influence on how Coltrane "would explore various permutations of limited sets of notes." Bair (2003) interprets a variety of cyclic progressions that can be found in short segments of "Venus," "Mars," "Jupiter," "Saturn," and "Offering" as analogous to, and potentially influenced by exercises found in Nicolas Slonimsky's Thesaurus of Scales and Melodic Patterns (1947).

${ }^{4}$ While Pressing's examination of "Offering" is the first to apply set theory to Coltrane's music, there are a few other examples in literature. Block (1990) describes the presence of interval cycles and trichordal sets within Coltrane's improvisation in Ascension (1966). Schott (2000) also labels pitch-class sets in his analysis in order to demonstrate structural unity. McGill's (2014) research uses set theory to investigate the influence of Dennis Sandole on Coltrane's development, exploring the possible link between the music of Arnold Schoenberg, Sandole's pedagogy, and Coltrane.

${ }^{5}$ Additional set-theoretic terminology is based broadly on that described by Forte (1973), Solomon (1982; 1998; 2005), and Straus (2000).
} 
Forte's (whose prime forms recognize equivalence among inversionally-related members) because Coltrane's improvisations predominantly demonstrate $T_{n}$ relationships.

Three small case studies from these recordings illustrate Coltrane's use of $(0,1,3),(0,2,4)$, and $(0,2,5)$ as they appear on the tracks "Iris" (from Stellar Regions) and "Saturn" (from Interstellar Space). The pc sets present in these two recordings exhibit the following characteristics:

1. Motives are frequently constructed from trichords, in a manner similar to structures found in twentieth-century atonal music.

2. Extended sections of Coltrane's improvisations contain various members of only one trichordal $\mathrm{T}_{\mathrm{n}}$-type.

3. A single pc set is often emphasized as a referential sonority, repeated, and juxtaposed with other members of the same $T_{n}$-type.

4. Common-tones are frequently used to "modulate" between trichords of the same $T_{n}$ type.

5. Pitch classes that appear as non-members within established sets often signal the forthcoming entrance of a set in which they are a member.

6. Trichordal sets are differentiated from one another through rhythm, contour, duration, rotation, and register.

CASE STUDY A - “IRIS"

This case study comprises three related analyses - set-theoretic, motivic, and harmonic - that illustrate the importance of $(0,1,3)$ as the structural foundation for the track "Iris" from Stellar 
Regions. The evidence of $(0,1,3)$ as a constant structure, used for the entirety of "Iris" by both the saxophone and piano, reveals a previously undocumented development in Coltrane's music, challenging the critical characterization of his late-period improvisations as unorganized and "free." "Iris" is extraordinary because it is the only piece in Coltrane's oeuvre where the theme, saxophone improvisation, and harmony are entirely derived from one trichordal $T_{n}$-type. An excerpt is shown in Figure 1. ${ }^{7}$ Neither Ascension nor "Acknowledgment" - both utilizing themes constructed from $(0,3,5)$ - achieve such homogeneity between these three elements.

\footnotetext{
${ }^{6}$ See Crouch (2006) and Dyer (2014) for recent critical characterizations of Coltrane's late-period music.

${ }^{7}$ A complete score analysis of 'Iris' will be published in a forthcoming PhD dissertation.
} 
Figure 1. "Iris" - saxophone, piano, bass concert score (00:00-00:26). ${ }^{8}$
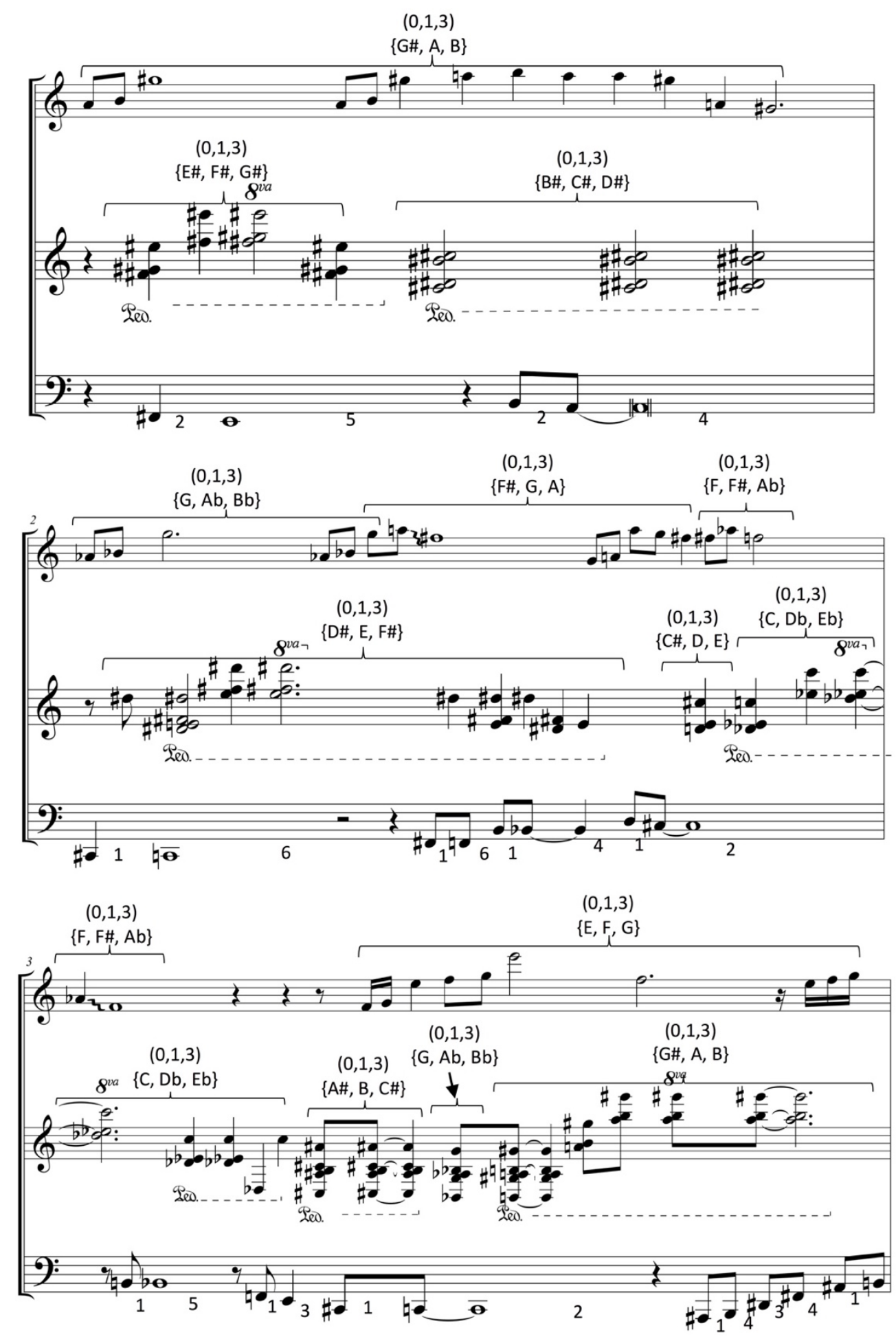

${ }^{8}$ All tenor saxophone parts in this article are written $8 v a$ in order to avoid clef changes. 
The analysis begins by cataloging the total number of occurrences of $(0,1,3)$ members in "Iris." Implied $(0,1,3)$ trichords which appear as sequential motivic fragments are not included in this tally of $(0,1,3)$ members. A count of the saxophone pc sets shows that all twelve members of $(0,1,3)$ are present with a total of 62 individual occurrences. The most frequent pc sets found are $\{A b, A, B\}$ and $\{D b, D, E\}$ which appear 8 times (Figure 2). Similarly, the piano contains all twelve members of $(0,1,3)$, with a total of 105 individual occurrences and the most frequent pc set $\{C, D b, E b\}$ (Figure 3).

Figure 2. Catalog of $(0,1,3)$ members (saxophone).

\begin{tabular}{|c|c|}
\hline Saxophone $T_{n}$-type $(0,1,3)$ Members & Number of Occurrences \\
\hline$\{A b, A, B\}$ & 8 \\
\hline$\{D b, D, E\}$ & 8 \\
\hline$\{D, E b, F\}$ & 7 \\
\hline$\{E b, E, F \#\}$ & 6 \\
\hline$\{F \#, G, A\}$ & 6 \\
\hline$\{C, D b, E b\}$ & 5 \\
\hline$\{F, F \#, A b\}$ & 5 \\
\hline$\{G, A b, B b\}$ & 4 \\
\hline$\{B, C, D\}$ & 3 \\
\hline$\{E, F, G\}$ & 2 \\
\hline$\{A, B b, C\}$ & 1 \\
\hline$\{B b, B, D b\}$ & \\
\hline
\end{tabular}


Figure 3. Catalog of $(0,1,3)$ members (piano).

\begin{tabular}{|c|c|}
\hline Piano $T_{n}$-type $(0,1,3)$ Members & Number of Occurrences \\
\hline$\{C, D b, E b\}$ & 16 \\
\hline$\{B, C, D\}$ & 12 \\
\hline$\{G \#, A, B\}$ & 12 \\
\hline$\{G, A b, B b\}$ & 11 \\
\hline$\{B b, B, C \#\}$ & 10 \\
\hline$\{F, G b, A b\}$ & 10 \\
\hline$\{F \#, G, A\}$ & 9 \\
\hline$\{C \#, D, E\}$ & 8 \\
\hline$\{D \#, E, F \#\}$ & 7 \\
\hline$\{D, E b, F\}$ & 5 \\
\hline$\{A, B b, C\}$ & 3 \\
\hline$\{E, F, G\}$ & 2 \\
\hline
\end{tabular}

No significant correlation is found between the most favored sets used by the saxophone and piano, indicating that their choices were most likely freely made. In "Iris" nearly twice as many members of $(0,1,3)$ are played by the piano as compared to the saxophone. These sets primarily overlap but on occasion they briefly synchronize. Figure 4 gives a general sense of these relationships, assigning a ratio (saxophone: piano) to illustrate the number of pc sets that occur in each voice during specific time-spans. This evidence demonstrates that the saxophone sets are predominantly harmonized with more than one trichord by the piano. 
Figure 4. Saxophone and piano pc set ratios.

\begin{tabular}{|c|c|}
\hline Time & Saxophone: Piano \\
\hline 00:00-00:08 & $1: 2$ \\
\hline 00:08-00:16 & $3: 3$ \\
\hline $00: 16-00: 26$ & $2: 4$ \\
\hline $00: 26-00: 34$ & $3: 2$ \\
\hline $00: 34-00: 45$ & $6: 6$ \\
\hline $00: 45-00: 55$ & $2: 3$ \\
\hline 00:55-01:01 & $1: 5$ \\
\hline 01:01-01:06 & $1: 5$ \\
\hline 01:06-01:11 & $2: 2$ \\
\hline 01:11-01:19 & $2: 3$ \\
\hline 01:19-01:26 & $2: 5$ \\
\hline $01: 26-01: 32$ & $3: 5$ \\
\hline 01:32-01:37 & $8: 1$ \\
\hline 01:37-01:41 & $2: 5$ \\
\hline 01:41-01:47 & $9: 5$ \\
\hline 01:47-01:53 & $6: 5$ \\
\hline
\end{tabular}

\begin{tabular}{|c|c|}
\hline Time & Saxophone: Piano \\
\hline $01: 53-01: 59$ & $3: 5$ \\
\hline $01: 59-02: 05$ & $2: 3$ \\
\hline $02: 05-02: 10$ & $2: 4$ \\
\hline $02: 10-02: 18$ & $2: 3$ \\
\hline $02: 18-02: 26$ & $6: 4$ \\
\hline $02: 26-02: 32$ & $2: 3$ \\
\hline $02: 32-02: 41$ & $4: 8$ \\
\hline $02: 41-02: 46$ & $2: 5$ \\
\hline $02: 46-02: 52$ & $3: 3$ \\
\hline $02: 52-02: 58$ & $4: 2$ \\
\hline $02: 58-03: 05$ & $4: 6$ \\
\hline $03: 05-03: 11$ & $6: 5$ \\
\hline $03: 11-03: 18$ & $5: 5$ \\
\hline $03: 18-03: 26$ & $2: 7$ \\
\hline $03: 26-03: 34$ & $3: 5$ \\
\hline $03: 34-03: 49$ & $1: 2$ \\
\hline
\end{tabular}

In "Iris" there is a strong correlation between the transposition operations used for members of $(0,1,3)$ and the interval content of this $T_{n}$-type. The combined occurrences of $T_{1} / T_{11}, T_{2} / T_{10}$, and $T_{3} / T_{9}$ in the piano represent 99 out of the $104 T_{n}$ operations occurring from set to set in "Iris" (Figure 5). A similar focus on these operations is found in the saxophone with $T_{1} / T_{11}, T_{2} / T_{10}$, and $T_{3} / T_{9}$ occurring in transpositions from set to set in all but three instances (Figure 6).

Figure $5 . T_{n}$ operations between members of $(0,1,3)$ in the piano.

\begin{tabular}{|c|c|}
\hline Piano Transpositions & Number of Occurrences \\
\hline $\mathrm{T}_{1} / \mathrm{T}_{11}$ & 57 \\
\hline $\mathrm{T}_{2} / \mathrm{T}_{10}$ & 31 \\
\hline $\mathrm{T}_{3} / \mathrm{T}_{9}$ & 11 \\
\hline $\mathrm{T}_{4} / \mathrm{T}_{8}$ & 2 \\
\hline $\mathrm{T}_{5} / \mathrm{T}_{7}$ & 3 \\
\hline $\mathrm{T}_{6}$ & 0 \\
\hline
\end{tabular}


Figure 6. $T_{n}$ operations between members of $(0,1,3)$ in the saxophone.

\begin{tabular}{|c|c|}
\hline Saxophone Transpositions & Number of Occurrences \\
\hline$T_{1} / T_{11}$ & 33 \\
\hline$T_{2} / T_{10}$ & 6 \\
\hline$T_{3} / T_{9}$ & 4 \\
\hline$T_{4} / T_{8}$ & 0 \\
\hline$T_{5} / T_{7}$ & 3 \\
\hline$T_{6}$ & 0 \\
\hline
\end{tabular}

An analysis of the bass content reveals no significant structural presence of $(0,1,3)$. However, the interval-class (ic) that does appear most often is ic1 (Figure 7). The chromatic movement of the bass sometimes results in its pitches becoming part of the trichords played by the saxophone and piano.

Figure 7. Frequency of interval-classes occurring in the bass.

\begin{tabular}{|c|c|}
\hline Bass Interval Content & Number of Occurrences \\
\hline Interval-Class 1: & 121 \\
\hline Interval-Class 2: & 53 \\
\hline Interval-Class 3: & 47 \\
\hline Interval-Class 4: & 48 \\
\hline Interval-Class 5: & 38 \\
\hline Interval-Class 6: & 11 \\
\hline
\end{tabular}

The continuous presence of members of $(0,1,3)$ in the saxophone and piano, as well as the correlation between the interval-class content (ic1, ic2, ic3) of $(0,1,3)$ and the most frequent $T_{n}$ operations that appear from set to set $\left(T_{1} / T_{11}, T_{2} / T_{10}, T_{3} / T_{9}\right)$, reveals that the intervallic components of $(0,1,3)$ project across multiple structural levels of "Iris." 
When exploring the structural content of the saxophone in more detail, other general characteristics emerge. The first-and arguably most important-feature found in Coltrane's improvisation is the use of common-tones when moving from set to set. Of the 82 sets identified, 76 share common-tones with neighbors. Figure 8 represents these sets vertically, with horizontal boxes connecting the common-tones. A frequent improvisatory technique uses the last pitch of the current set being played, as the first pitch in a new set transposition (Figure 9a, 9b, and 9c). 
Figure 8. "Iris": saxophone set sequence, $T_{n}$ relations, and common-tone structure. ${ }^{9}$

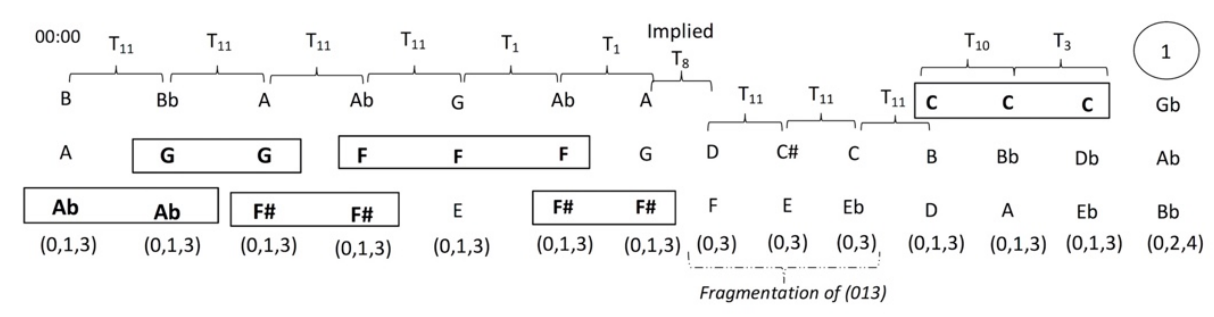

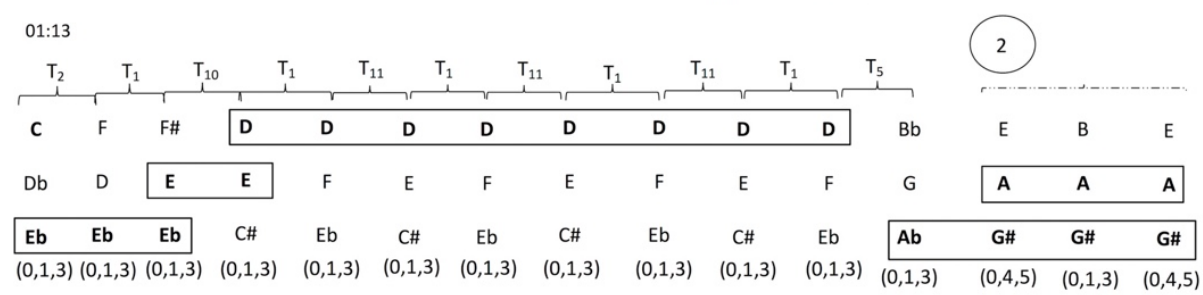

\begin{tabular}{|c|c|c|c|c|c|c|c|c|c|c|c|c|c|}
\hline 01:43 & & ommon-1 & e Synthe & s of Two $T$ & richordal & t Classes & & & Impl & ed & $\underbrace{T_{1}}$ & $\mathrm{~T}_{3}$ & \\
\hline $\mathrm{E}$ & B & E & B & $\mathrm{E}$ & B & $\mathrm{E}$ & B & $\mathrm{E}$ & B & C & C & c & F\# \\
\hline A & A & A & A & A & A & A & A & A & A & A & B & $\mathrm{Db}$ & $\mathrm{E}$ \\
\hline G\# & G\# & G\# & G\# & G\# & G\# & G\# & G\# & G\# & & $\mathrm{Bb}$ & D & Eb & Eb \\
\hline$(0,4,5)$ & $(0,1,3)$ & $(0,4,5$ & $(0,1,3)$ & $(0,4,5)$ & $(0,1,3)$ & $(0,4,5)$ & $(0,1,3)$ & $(0,4,5)$ & $\begin{array}{l}(0,1,3) \\
\text { Frag. }\end{array}$ & $(0,1,3)$ & $(0,1,3)$ & $(0,1,3)$ & $(0,1,3)$ \\
\hline
\end{tabular}
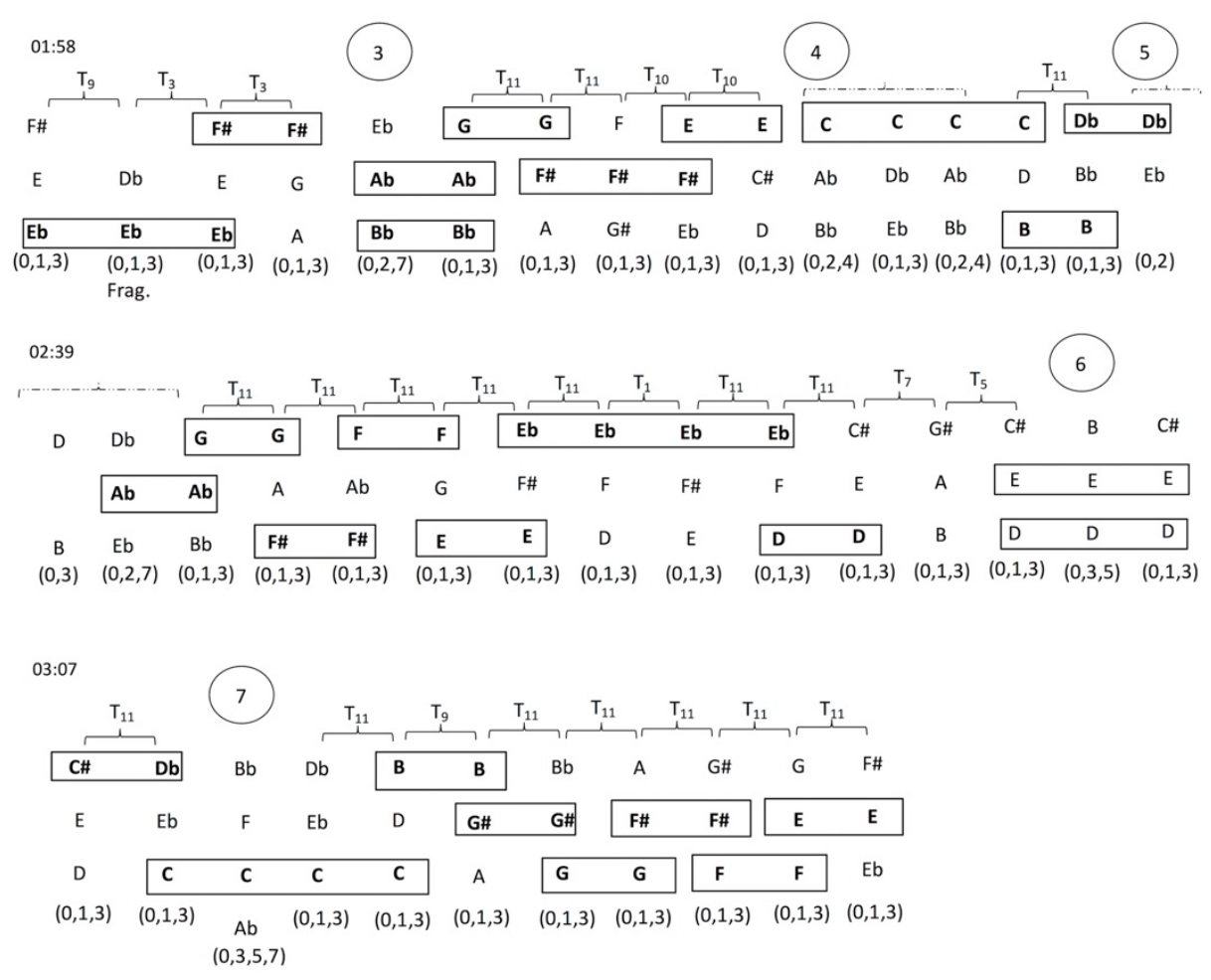

\footnotetext{
${ }^{9}$ Numbered circles are explained in the following paragraphs.
} 
Figure 9a. Set linking by common-tone (00:08).

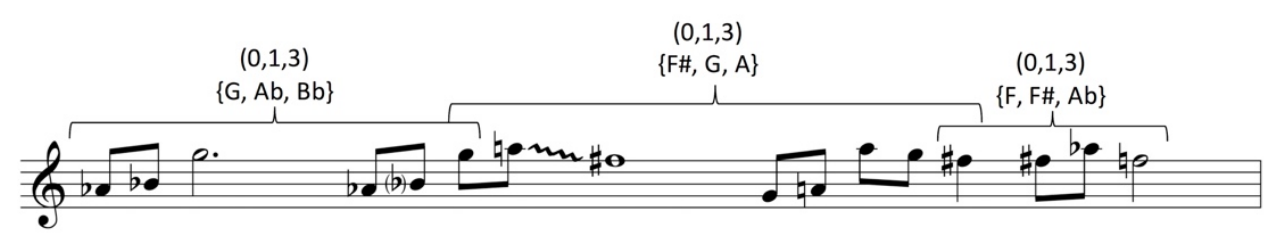

Figure 9b. (01:59).

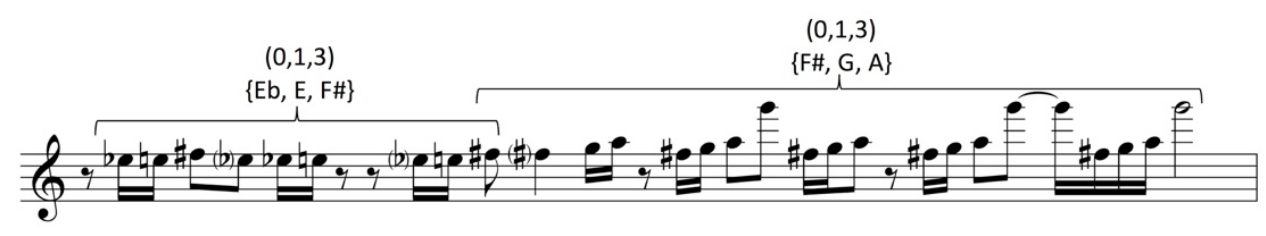

Figure 9c. (02:46).

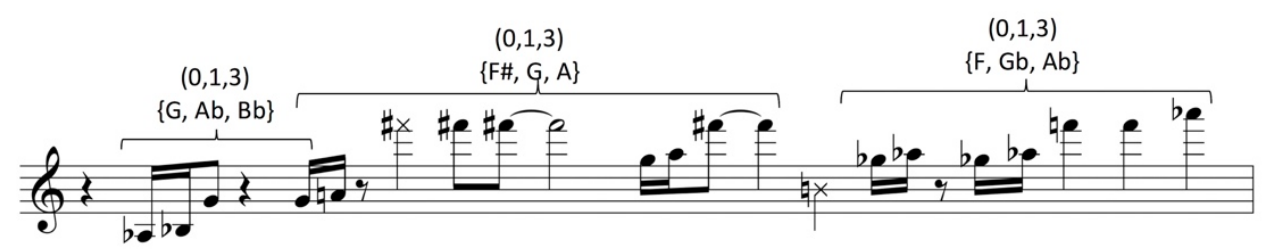

In one of the most compelling examples of common-tone connections between sets, Coltrane uses the pitch $D$ as a pivot between $\{C \#, D, E\}$ and $\{D, E b, F\}$, combining them into one repeated descending melodic structure (Figure 10). This event undergoes imitation and modification only moments later with $(0,1,3)$ and $(0,4,5)$. In Figure $11\{E, G \#, A\}$, a member of $(0,4,5)$, appears as an expansion of $(0,1,3)$. Pitch classes $G \#$ and $A$ are then used as common-tones between $\{G \#, A, B\}$ and $\{E, G \#, A\}$ in a repeated descending gesture.

Figure 10. Common-tone synthesis of $\{C \#, D, E\}$ and $\{D, E b, F\}(01: 31)$.

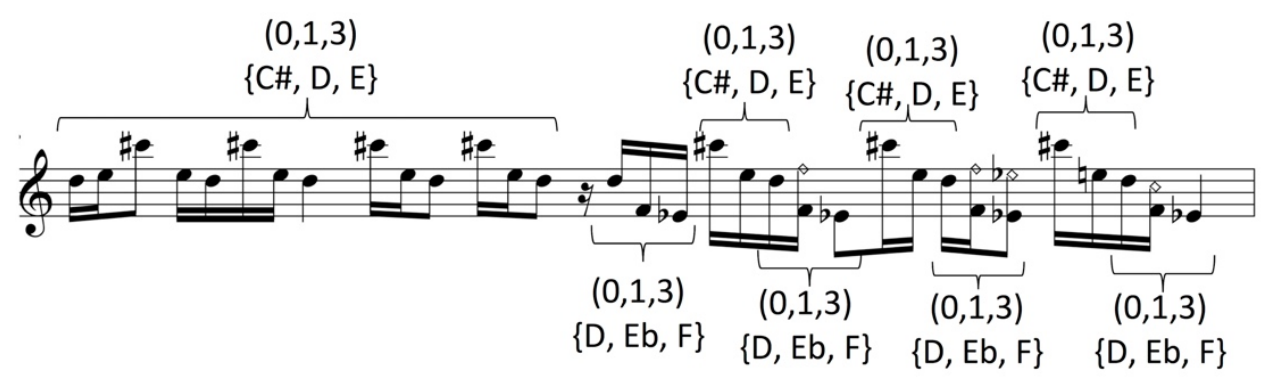


Figure 11. Common-tone synthesis of $(0,1,3)$ and $(0,4,5)(01: 40)$.

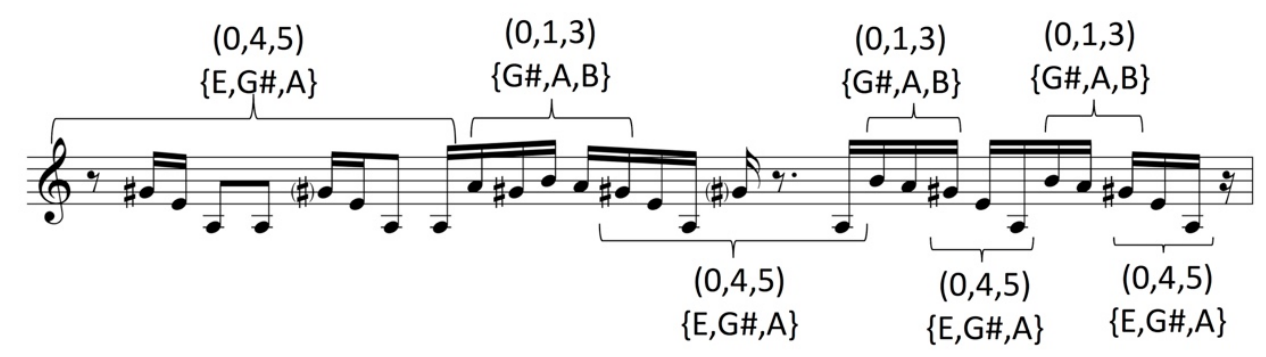

During the entire length of "Iris" there are only seven brief instances in which the pitch content played by Coltrane does not adhere to the $(0,1,3)$ structure. These places where Coltrane strays from $(0,1,3)$ are significant because they demonstrate two things: $(1)$ a plasticity in how Coltrane uses pc sets; and (2) dedication to the structural prominence of $(0,1,3)$, signified by its return after each divergent event. It is for this reason that these events are identified as divergences from $(0,1,3)$ in the analysis. In Figure 8 seven divergent events are identified with a circle containing a number for each instance. The significant feature of all of these divergences is that they exist in dialogue with the events that precede and follow them, as illustrated in the next two examples.

In the first example (divergence \#4) Coltrane uses the note $\mathrm{C}$ as an upper-register common-tone anchor for $\{A b, B b, C\},\{C, D b, E b\}$, and $\{B, C, D\}$. Pitch-class set $\{A b, B b, C\}-$ a member of $(0,2,4)-$ first interrupts the modulation from $\{C \#, D, E\}$ to $\{C, D b, E b\}$, then interrupts again between $\{C, D b, E b\}$ and $\{B, C, D\}$ (Figure 12). The elimination of $\{A b, B b, C\}$ from the set sequence reveals the descending semitone transpositional pattern $\{C \#, D, E\},\{C, D b, E b\},\{B, C, D\}$.

Figure 12. $(0,1,3)$ divergence \#4 (02:23).

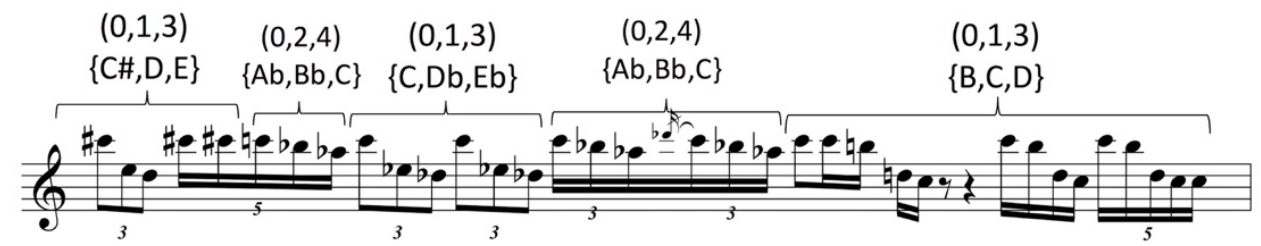


In the second example (divergence \#6) $T_{n}$-type $(0,3,5)$ emerges as an expansion of $(0,1,3)$. Within the set pattern $\{C \#, D, E\},\{B, D, E\},\{C \#, D, E\}$, pitch-classes $D$ and $E$ are retained between the pc sets (Figure 13).

Figure 13. $(0,1,3)$ divergence \#6 (03:04).

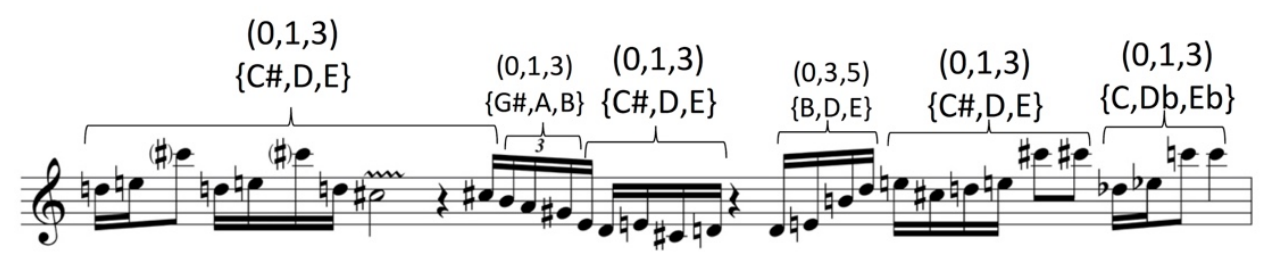

While these are only two examples, all seven divergences reside within the context of an extraordinarily consistent use of $(0,1,3)$. A plasticity is demonstrated in the way Coltrane improvises within the parameters of this $T_{n}$-type with each divergence characterized by a unique relationship to $(0,1,3)$. Additionally, the use of common-tone connections between pc sets emerges as the principal structural device in "Iris."

\section{MOTIVIC RELATIONSHIPS AND SURFACES}

The relationship between the motivic structures in the saxophone, and the rotational permutations and interval content of $(0,1,3)$ will now be examined. The initial ascending threenote motive played by Coltrane, $A-B-G \#$, is perhaps the most important gesture in "Iris." The structure of this figure also represents one of the primary chord voicings used by the piano. While this is a significant recurring motive, many others appear as well.

The motives that appear between 00:00-00:56 are analyzed within the context of the six rotations of $(0,1,3)$. These comprise ordered pc sets in normal order, first and second rotations, and their corresponding retrogrades. These six basic formations are referred to in the analysis as "rotational motives" (or RMs) and given the designations N, N1, N2, R, R1, and R2 (Figure 14) in order to identify the specific motivic contours that are present. 
Figure 14. Analytical labels for the six rotational motives.

\begin{tabular}{|c|c|c|}
\hline $\mathrm{N}$ & $\mathrm{N} 1$ & $\mathrm{~N} 2$ \\
Normal Order & First Rotation & Second Rotation \\
$\{0,1,3\}$ & $\{1,3,0\}$ & $\{3,0,1\}$ \\
\hline $\mathrm{R}$ & $\mathrm{R} 1$ & $\mathrm{R} 2$ \\
Retrograde Normal Order & Retrograde First Rotation & Retrograde Second Rotation \\
$\{3,1,0\}$ & $\{1,0,3\}$ & $\{0,3,1\}$ \\
\hline
\end{tabular}

Within the saxophone improvisation, both $\mathrm{N}$ and $\mathrm{R}$ always sound as scale-like figures. However, there are two different melodic contours that use different registers for N1, R1, and R2. These contour forms are indicated in the analysis by the labels N1a and N1b, R1a and R1b, and R2a and R2b (Figure 15). Curiously, there is no clear statement of N2 (with rhythmic emphasis or repetition) by Coltrane in "Iris."

Figure 15. Contour forms of N1, R1, and R2.
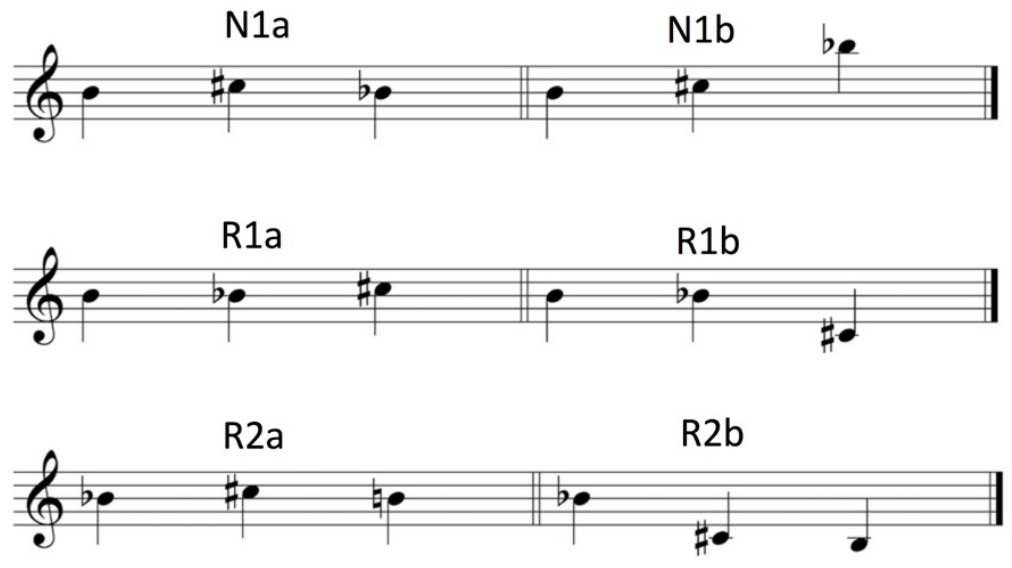

These RMs can be recognized as overlapping structures within a larger, scale-like pattern (Figure 16). This formation is an important background structure that occurs throughout the saxophone improvisation and is referenced in the analysis as "scale" $(0,1,3)$. 
Figure 16. "Scale" $(0,1,3)$.

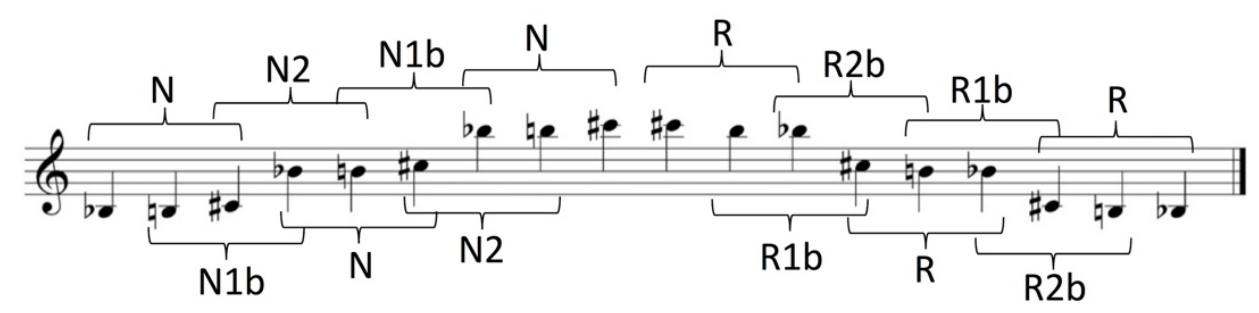

RMs are often rhythmically stressed in a way that emphasizes their contour and trichordal structure. Phrases are generally built from stringing several RMs together, or from RMs that overlap. Sometimes phrases are built using a sequence of contiguous two-note and three-note segments from scale $(0,1,3)$. At other times RMs are broken into their dyad subsets and then juxtaposed in different octaves (e.g., $\{C, E b\}$ and $\{D b, E b\})$. Additionally, dyad subsets of RMs may appear as anticipations or extensions of RMs. The following analysis illustrates how these elements emerge and combine over a larger time span to create a complex melodic fabric.

Five phrases with irregular lengths and similar ascending and descending contours appear between 00:00 and 00:56 (Figure 17). Phrases one, two, and three follow a similar pattern, beginning with two statements of N1b, followed by a sequence of RMs that end on a dyad subset of R. Phrases four and five continue the ascending and descending contour while introducing new RMs (R1a, R1b, R2a, R2b). A glissando gesture spanning the interval of a descending minor third is another important figure developed during this section. It first appears as part of the contour of N1a and then develops as an extension of other RMs. Scale $(0,1,3)$ emerges as a recurring background figure throughout this entire section, providing continuity between the five phrases.

In phrase one, after the initial presentation of N1b, the overlapping of N1b, N, and R relate as a segment of scale $(0,1,3)$ missing only one pitch $(B)$. The pitches $A$ and $G \#$, an $(0,1)$ dyad subset of $R$, completes phrase one and echoes the final two pitches of $R$ one octave lower. An antecedent-consequent relationship emerges between phrases one and two. 
Phrase two begins with the sequence N1b, N1b, and N1a whereby the N1a motive appears as a contrasting contour to the first two statements of N1b. Here N1b and N1a overlap and share the common tone $G$ as a result of the modulation from $\{G, A b, B b\}$ to $\{F \#, G, A\}$, rhythmically unified into one gesture. An important recurring melodic gesture in this section is the glissando, which first appears within the contour of N1a from A to F\# $(0,3)$. Pitches $G$ and $A-$ an $(0,2)$ dyad subset of $\mathrm{R}$ - begin the next ascending gesture, with its contour at first suggesting the beginning of another N1b motive. Instead the contour changes direction and R follows, with the contour of R echoing the A-F\# glissando in N1a. A second occurrence of N1a in this phrase reinforces its earlier appearance and is followed by an Ab-F glissando - an $(0,3)$ subset of N1a - to conclude the phrase.

Phrase three begins once more with a sequence of two N1b motives. This time they are played more rapidly and span two octaves, ending on the descending figure $E$ to $F$ (an extension and subset of N1b). Here the ordered pitch interval -11 (between E and F), which has previous only appeared as an incidental intervallic structure in phrase one and two, takes on more prominence due to the rhythmic stress on the note $F$. The second half of this phrase is a development and elaboration of the first half, rhythmically connecting the overlapping $\mathrm{N}$ and N1b motives to create the four-note figure $E-F-G-E$. This mimics the first half of the phrase, where there is a nested appearance of overlapping $\mathrm{N}$ and N1b motives within N1b-N1b. The descending figure $E$ to $F(-11)$ reappears and is now embedded within the consecutive motives $\mathrm{R}$ and $\mathrm{N}$, with the pitch $\mathrm{F}$ again sustained and rhythmically stressed. In the last figure in this phrase, the appearance of scale $(0,1,3)$ references the first phrase, while the descending glissando from $A b$ to $F(0,3)$ echoes the final glissando gesture at end of the second phrase. In this way, the ending of phrase three synthesizes the endings of phrases one and two.

Breaking from the pattern in the previous three phrases, phrase four begins with $\mathrm{N}$ and the first appearance of R1a and R1b (the contrasting contour for R1a). A descending minor third glissando gesture and $(0,3)$ subset of $R 1 b(A-F \#)$ extends the phrase, generating a series of 
$(0,3)$ dyads that descend by semitone. Here an ordered pitch interval of +11 is seen between $\mathrm{F \#}$ and $\mathrm{F}$ which mirrors the previous occurrences of -11 in phrase one, two, and three.

The final phrase begins with the first appearance of R2a. The rhythmic momentum begins to build as the sequence of $N, N, N, R, R$ reveals a complete segment of scale $(0,1,3)$ that spans two octaves. This scale $(0,1,3)$ segment ends with an extension of $R$ using the pitches $C$ and $B-$ an $(0,1)$ subset of $R$. As the next figure begins, R2b makes its first appearance as a rapid repeated motive which builds in intensity, eventually developing into repeated segments of scale $(0,1,3)$.

Figure 17. "Iris" saxophone motivic analysis (excerpts: phrase 1, 4, and 5).
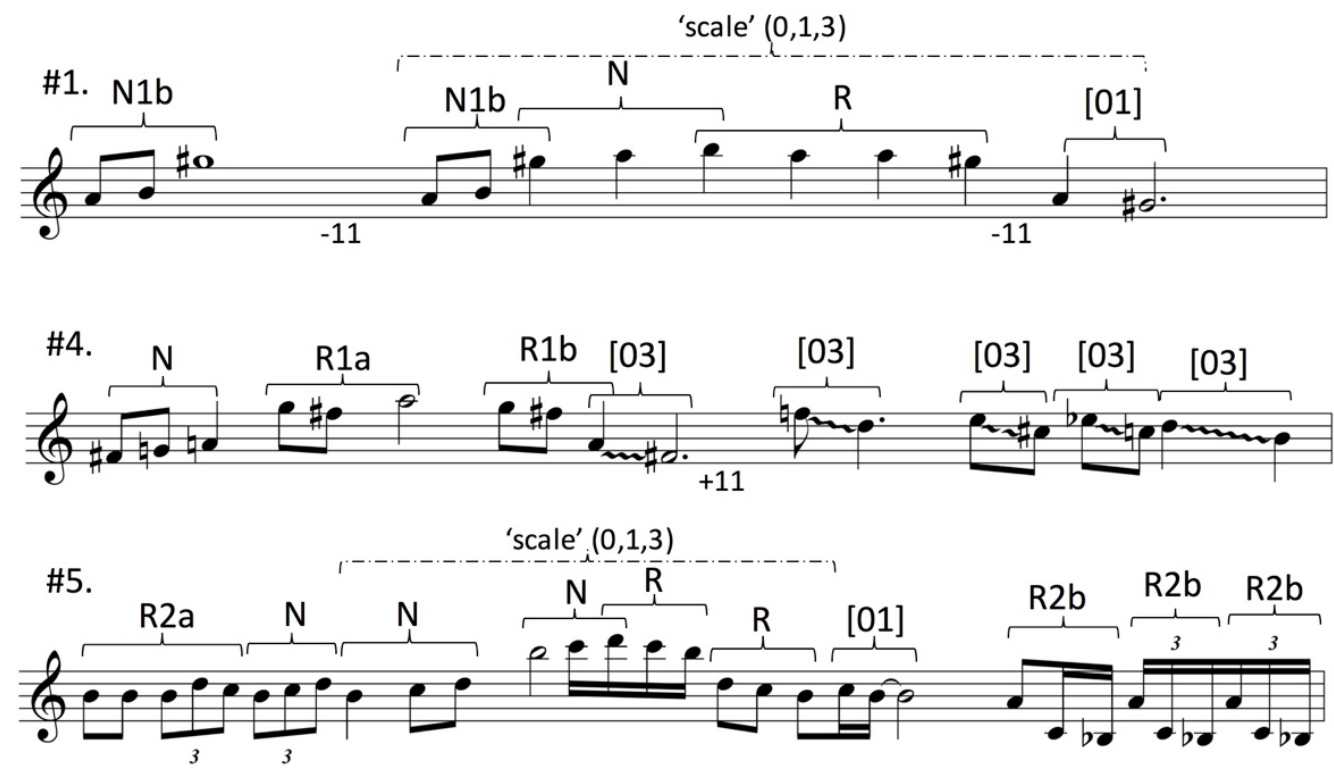

This analysis illustrates some of the ways that Coltrane uses motives to build up the melodic surface of "Iris." Motivic contours that reflect the rotational structures within $(0,1,3)$ appear in complex patterns. Six overlapping RMs are shown forming scale $(0,1,3)$ from which segments frequently emerge. Dyad subsets of the RMs appear at times in different octaves, and as motivic gestures anticipating or extending RMs. Phrases of various lengths display antecedentconsequent relationships within a larger emerging structural pattern. The continuing 
investigation of the saxophone's pitch content places it within the context of the harmonic interactions of all three instruments.

HARMONIC STABILITY, DISSONANCE, AND PC SET INTERACTIONS

"Iris" has an elusive harmonic quality, suggestive of both tonality and atonality. Research into the perception of structural stability in atonal music suggests that listeners hear in terms of structural importance and are influenced by issues such as metrical and durational structure, dissonance, and the horizontal movement of voices. ${ }^{10}$ In order to better understand the significance of the pitch structure in "Iris" and those factors that influence harmonic perception, the analysis begins by reflecting on its pc set structure within the context of Coltrane's other late work.

A survey of Coltrane's recordings from 1967 reveals three other compositions ("Expression," "To Be," and "Offering") that are stylistically similar to "Iris." ${ }^{11}$ All are rubato-ballads that have harmonic progressions with tonal qualities. ${ }^{12}$ These pieces also share a similar formal narrative, beginning with a flexible theme and harmony, followed by an eventual dissolution into improvisation. In "Expression," "To Be," and "Offering" however, the theme's chord voicings and harmonies are types typically used in tonal jazz, suggesting functional relationships which support the melody rhythmically. The sheet music to "Expression", published in The New Real Book Vol. 2, demonstrates how this composition can easily be represented in the conventional lead sheet format of melody and chord changes (Bauer and Sher 1991). In contrast, the harmonic effects in "Iris" are dependent upon the contrapuntal interaction of the three instruments.

Harmonic stability constantly fluctuates in "Iris" due to the set interactions of the saxophone and piano. In order to better understand this harmonic interplay, I will examine the sets that result

\footnotetext{
${ }^{10}$ For example, see Dibben (1999).

${ }^{11}$ Although "Offering" was recorded at the same session that produced Stellar Regions, it was originally released along with "Expression" and "To Be" on Expression (1967).

12 The term "rubato-ballad" was first coined by Jost $(1975,102)$ to describe a type of Coltrane composition that defies the typical conventions of a ballad.
} 
from the combination of two members of $(0,1,3)$ at all intervals of transposition. Figure 18 shows the six collections that are produced from these mergers. The two most dissonant combinations, $(0,1,2,3,4)$ and $(0,1,2,3,5)$, contain the highest number of ic1 and ic 2 in their interval vectors and result from merging $p c$ sets related at $T_{1} / T_{11}$ and $T_{2} / T_{10}$. Although the interval vector of $(0,1,3,4,5,7)$ has the same number of occurrences of ic1 and ic2 as $(0,1,2,3,5)$, the total distribution of its intervals is weighted towards those that are consonant. Further examination of four of these collections reveals they are subsets of three larger supersets: the octatonic collection, Olivier Messiaen's third mode of limited transposition, and the Locrian hexachord. ${ }^{13}$ Thus, when $(0,1,3)$ members are related at $T_{3} / T_{9}, T_{4} / T_{8}, T_{5} / T_{7}$, or $T_{6}$, they tend to reflect the harmonic characteristics of these supersets. In instances where $(0,1,3)$ sets are related at $T_{1} / T_{11}$ or $T_{2} / T_{10}$, chromatic clusters are present and dissonance tends to increase.

Figure $18 . T_{n}$-types that result from merging two members of $(0,1,3) .{ }^{14}$

\begin{tabular}{|c|c|c|c|c|}
\hline$(0,1,3)$ PC Sets & $T_{n}$ Operation & $T_{n}$-type & IC Vector & Quality \\
\hline$a+b$ & $T_{1}, T_{11}$ & $(0,1,2,3,4)$ & $<432100\rangle$ & $\begin{array}{l}\text { Chromatic } \\
\text { Pentamirror }\end{array}$ \\
\hline$a+b$ & $T_{2}, T_{10}$ & $(0,1,2,3,5)$ & $<332110\rangle$ & $\begin{array}{l}\text { Major Second } \\
\text { Pentacluster }\end{array}$ \\
\hline$a+b$ & $\mathrm{~T}_{3}, \mathrm{~T}_{9}$ & $(0,1,3,4,6)$ & $<223111>$ & Octatonic Subset \\
\hline$a+b$ & $\mathrm{~T}_{4}, \mathrm{~T}_{8}$ & $(0,1,3,4,5,7)$ & $<333321>$ & $\begin{array}{l}\text { Messiaen's Third } \\
\text { Mode Subset }\end{array}$ \\
\hline$a+b$ & $T_{5}, T_{7}$ & $(0,1,3,5,6,8)$ & $<233241>$ & $\begin{array}{l}\text { Locrian } \\
\text { Hexachord }\end{array}$ \\
\hline$a+b$ & $\mathrm{~T}_{6}$ & $(0,1,3,6,7,9)$ & $<224223>$ & Octatonic Subset \\
\hline
\end{tabular}

It is important to acknowledge a harmonic quality inherent in the structure of $(0,1,3)$ which implies chord tones 1, 7, and 9 of a major-seventh chord. All the tones of a major-seventh chord (with the addition of the ninth and eleventh) are represented when members of $(0,1,3)$ related at $T_{5} / T_{7}$ are merged. An example of this occurs in Figure 20 , when sets $\{B \#, C \#, D \#\}$ and $\{E \#, F \#, G \#\}$

\footnotetext{
${ }^{13}$ The construction of Messiaen's third mode is $(0,2,3,4,6,7,8, T, E)$ (Messiaen 1956).

${ }^{14}$ The descriptive qualities "chromatic pentamirror" and "major second petacluster" in Figure 18 appear in Solomon's table of pc sets (2005).
} 
are sounded together, implying harmonically a C\# major-seventh chord. This is examined in more detail in the upcoming analysis.

While the dialogue between the $(0,1,3)$ sets in the saxophone and piano is important as to how the harmony is perceived, the bass pitches exert tremendous influence on the final harmonic result, acting independently of the $(0,1,3)$ structure and relating to the other voices in three ways: (1) by alternately supporting one of the voices via consonant interval relationships; (2) by synthesizing all the voices into a cohesive harmonic sonority; (3) by acting to negate the harmonic activity of the other parts. Pedal points are established by the bass periodically throughout "Iris," temporarily creating pitch centricity with which the other voices interact. As the music builds in intensity, it also becomes more harmonically unstable due to the greater pitch and rhythmic activity in the bass. The drums mirror the bass activity, beginning with a light, textural effect on brushes, which is followed by a change to sticks as the music intensifies and rhythmic propulsion builds.

The following analysis of the opening section of "Iris" illustrates the harmonic interactions of the $(0,1,3)$ sets and the bass's influence upon them, identifying transient harmonies with chord symbols that reflect the harmonic qualities. Additionally, other factors emerge in the analysis (such as rhythmic synchrony, pitch duration, and pc set duration) that influence harmonic perception.

The first phrase of "Iris" contains the implied harmonic progression F\#min ${ }^{(\text {Maj7) }}, F \# m_{i n}^{(M a j 7)} / E$, $A M a j 7^{(\# 9, \# 11)}$, resulting from the interaction of the three instruments (Figure 19). The duration of $\{G \#, A, B\}-$ played by the saxophone for the entire phrase-establishes a temporary harmonic

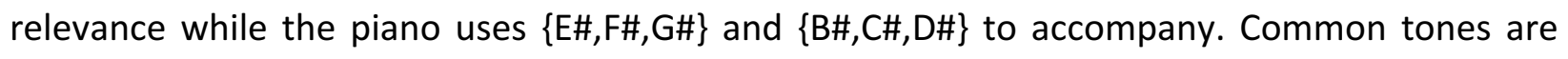
found between the three instruments throughout the phrase: initially with F\# (between the piano and bass) and G\# (between the saxophone and piano), and at the end of the phrase with $A$ and $B$ (between the bass and saxophone). Harmonic tension increases at the beginning of the phrase when the bass moves to the note $E$ (which conflicts with the established F\# minor major-seventh 
sonority sustained by the piano and saxophone), and in the second half of the phrase (due to the conflict between the B in the saxophone and bass and the B\# sustained by the piano). Tension in the phrase is then released upon the arrival of the note $A$ (sustained in the bass). The $\{B \#, C \#, D \#\}$ sustained in the piano, in combination with the saxophone's A and G\#, and the A sustained by the bass, implies an A major-seventh chord with a sharp ninth (B\#), and a sharp eleventh (D\#). Alternatively, this sonority could be interpreted as a C\# major-ninth chord with no third over A in the bass.

Figure 19. "Iris" harmonic properties and pc set interactions (00:00 - 00:08).

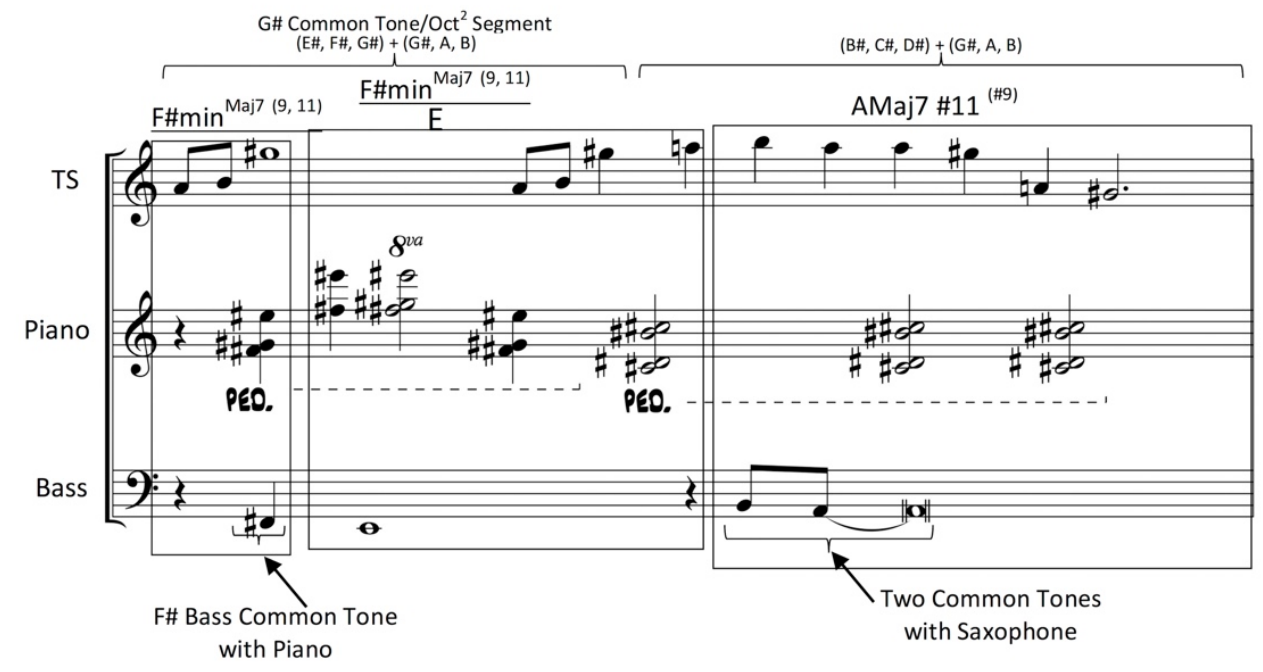

As the second phrase begins (Figure 20), the bass and piano entrances anticipate the first and third notes of the saxophone's melodic gesture, creating the sense of a unified harmonic rhythm. In this phrase, the saxophone and piano each use three pc sets which overlap and are sustained for different durations. The interaction of these sets with the bass implies the chord progression C7 ${ }^{(\# 9, \# 11, b 13)}$, Bsus, D\#min/A\#, DMaj7/C\#, C\#Maj9. The harmonic stability of the phrase is reinforced where notes with consonant interval relationships either rhythmically synchronize, or occur in very close rhythmic proximity. This is seen initially in the saxophone and bass with the P5-related pitches $\mathrm{C \#}$ and $\mathrm{Ab}(\mathrm{G \# )}$, C and G (with the added rhythmic support of the piano's entrance), and later with D and A (between the bass and saxophone). The phrase ends with the saxophone and piano in virtual rhythmic synchrony, reinforcing the chord progression DMaj7/C\# to C\#Maj7. Here F\# and G\# in the saxophone function as the third and 
sharp-eleventh of a D major-seventh chord and E\# functions as the third of a C\# major-seventh chord.

Harmonic stability is also reinforced in this phrase by the sustained pitches $G, F \#$, and E\# in the saxophone and $C, A \#, C \#$, and $A \#$ in the bass. The piano trichord $\{D \#, E, F \#\}$ is sustained for most of this phrase, allowing the melodic content of the other instruments to embellish its harmonic character. Additional stabilizing elements in this phrase are the sustained F\# in the saxophone (shared with the piano), and the sustained C\# in the bass (also shared with the piano).

In the final gesture of this phrase the bass exerts an important influence on the harmony. While the saxophone and piano sustain their pitch content, the bass notes B and A\# shift the sonority of this harmony from C\# major-seventh to A\# minor (Figure 20). Additionally, this suggests a passing B dominant-seventh before the A\# minor harmony. As "Iris" develops, this pattern of harmonic innuendo and chromatic tension-and-release continues.

Figure 20. "Iris" harmonic properties and set interaction (00:08 - 00:18).

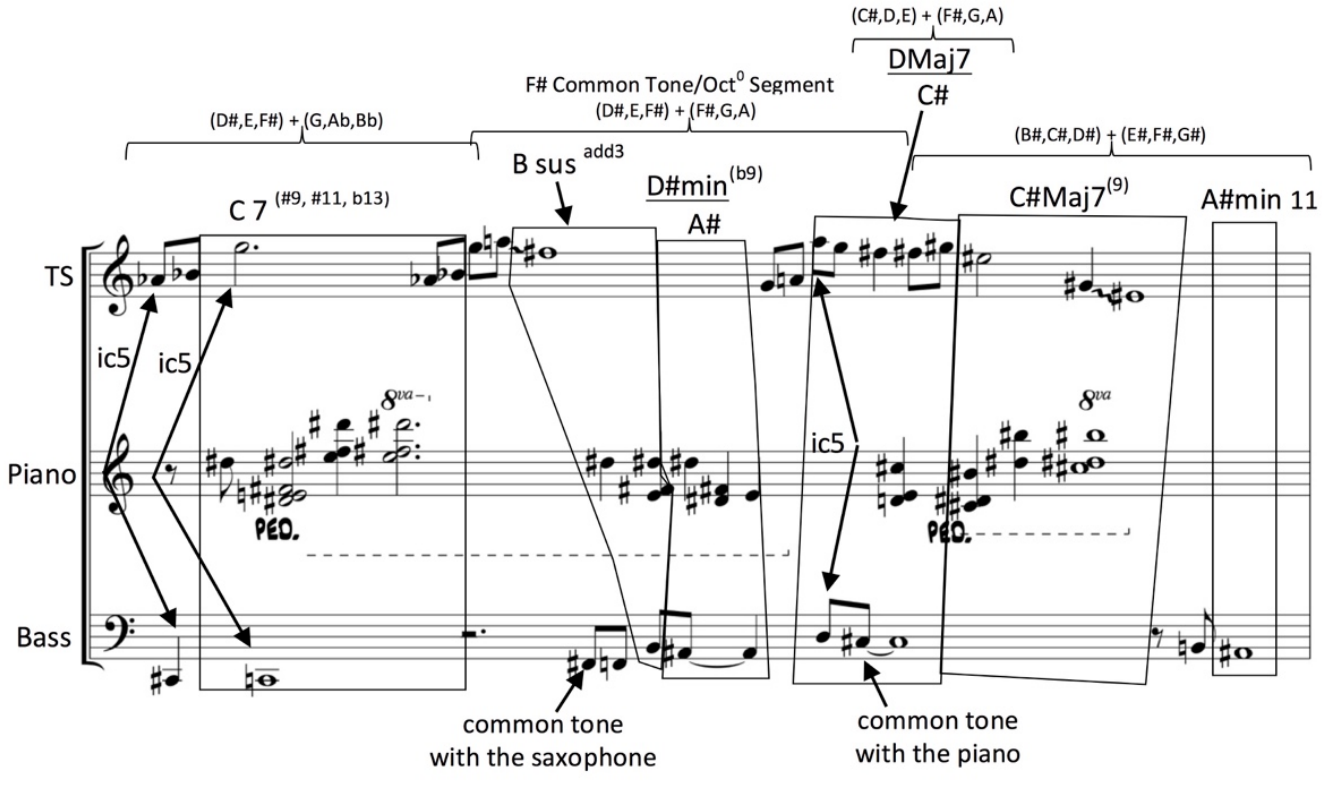


The beginning of "Iris" contains some of the most consonant and recognizable harmonies in the piece. The evidence presented demonstrates how the horizontal movement of each instrument, pitch-class set interactions, pitch and pc set duration, common tones between voices, rhythmic synchrony, and gestural anticipation all influence the perception of harmonic stability. Furthermore, the harmonies that result from the $(0,1,3)$ set interactions are contained within six larger collections with distinct harmonic characteristics, demonstrating a harmonic structure in "Iris" that is unique not only among Coltrane's rubato-ballads of 1967, but in his discography as well.

The structure of "Iris" is significant because it reveals a previously undocumented process in Coltrane's work, prompting a reassessment of how we think about his late-period music (and free jazz more generally). Because of the continuous presence of $(0,1,3)$ as a structural determinant for the piano and saxophone pitch content, "Iris" establishes a clear precedent for trichordal formations found throughout Coltrane's other improvisations on Interstellar Space and Stellar Regions. Case Studies B and C now investigate how this structural model emerges in "Saturn," from Interstellar Space.

\section{CASE STUDY B - "SATURN" ANALYSIS 1}

This second case study presents evidence of $T_{n}$-type $(0,2,4)$ as the structural foundation for one section of Coltrane's improvisation in "Saturn." Among the six tracks on Interstellar Space (a duo of John Coltrane on tenor saxophone and Rashied Ali on drums), "Saturn" displays the greatest variety of trichordal $\mathrm{T}_{\mathrm{n}}$-types developed for prolonged durations, with consecutive sections focused on $(0,2,4),(0,1,3),(0,2,5)$ and $(0,2,7)$ between 3:20 and 8:00. After a brief drum introduction, "Saturn" begins with a minor blues theme in 3/4 meter with a ternary form of A-BA. Tonality and meter gradually dissolve after the statement of the theme, and Coltrane's improvisation becomes free of any references to them until the recapitulation. 
Members of $(0,2,4)$ appear shortly after the theme at 3:20, continuing for one minute and forty seconds with only one brief interruption. Here Coltrane uses common-tone connections between pc sets less frequently than in "Iris," possibly to avoid frequent whole-tone scale references. A distinguishing feature throughout the first minute of this section is the referential use of the initial set $\{F \#, G \#, A \#\}$ through its frequent emphasis and juxtaposition with six other $T_{n}$-related sets. While the use of $\{F \#, G \#, A \#\}$ as a referential set is important, a more significant structural device emerges, spanning this entire section. This device utilizes repeated pairs of $T_{n}$-related $(0,2,4)$ sets, which result in distinct harmonic regions that collectively elicit a larger narrative arc.

Between 3:20 and 5:01, a total of seven sections appear with repeated pairs of $T_{n}$-related $(0,2,4)$ sets (Figure 21). The transitions connecting these seven sections contain set sequences with a variety of features.

Figure 21. Seven sections with multiple repetitions of two $T_{n}$-related trichords.

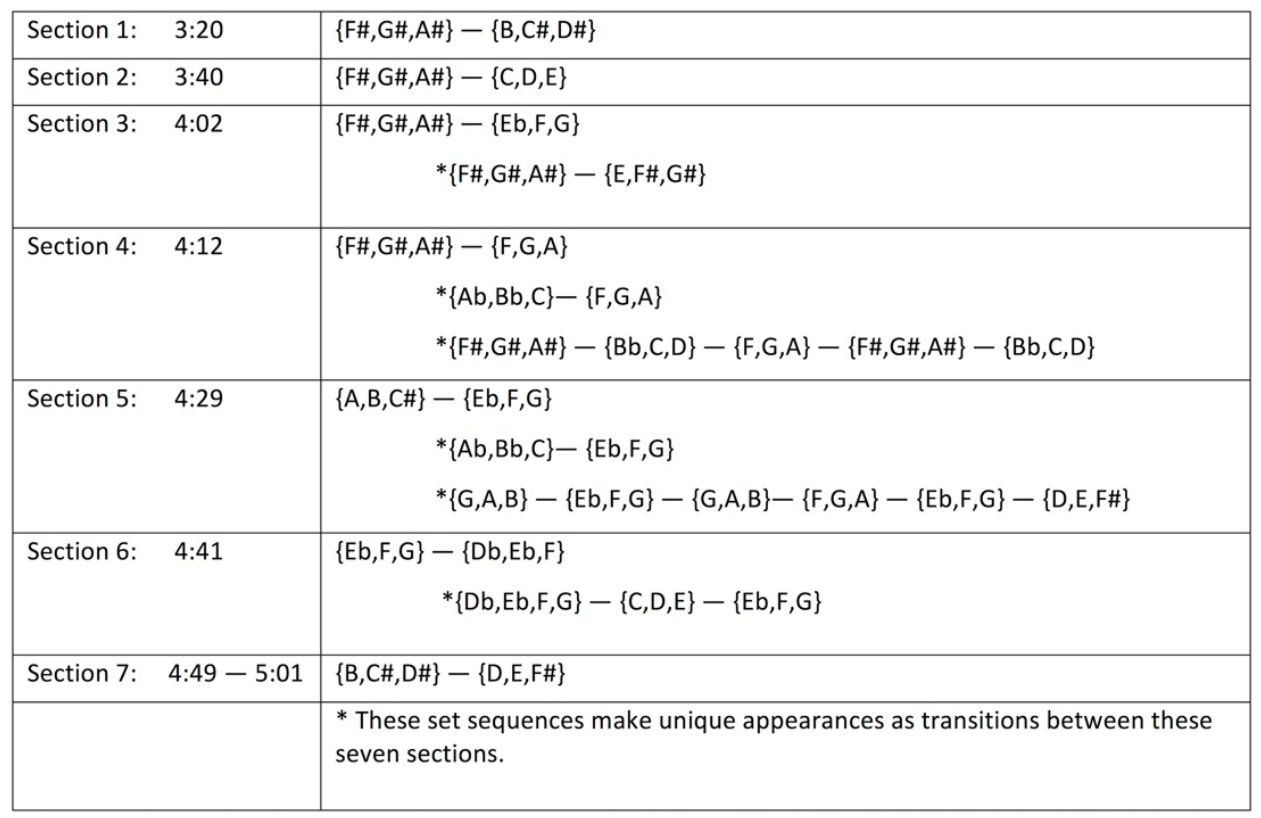

A closer examination of these transitions begins with the sequence of pc sets occurring between sections 3 and 4. Here, a gradual transpositional compression occurs between the referential pc 
set $\{F \#, G \#, A \#\}$ and the contrasting transpositions $\{E b, F, G\},\{E, F \#, G \#\}$ and $\{F, G, A\}$. This results in an ascending semitonal voice-leading movement between the contrasting pc sets. In order to illustrate the transpositional mapping that occurs between sections 4 and 5, Figure 22 groups the trichords into subdivisions of two and three sets. This transition begins with the substitution of $\{A b, B b, C\}$ for $\{F \#, G \#, A \#\}$; mapping at $T_{2}$ and disrupting the previously repeated pattern of $\{F \#, G \#, A \#\}-\{F, G, A\}$. Trichord $\{A b, B b, C\}$ then maps back onto $\{F \#, G \#, A \#\}$ at $T_{10}$, returning to the repeated pattern $\{F \#, G \#, A \#\}-\{F, G, A\}$. This is followed by the insertion of $\{B b, C, D\}$ between these two trichords, creating an expanded three-set pattern of $\{F \#, G \#, A \#\},\{B b, C, D\},\{F, G, A\}$. This pattern is then repeated, substituting $\{A, B, C \#\}$ for $\{F, G, A\}$ and mapping at $T_{4}$. Section 5 begins upon the arrival of $\{A, B, C \#\}$ and its contrasting trichord $\{E b, F, G\}$.

Figure 22. Transition from Section 4 to Section 5 (04:12 - 04:29).

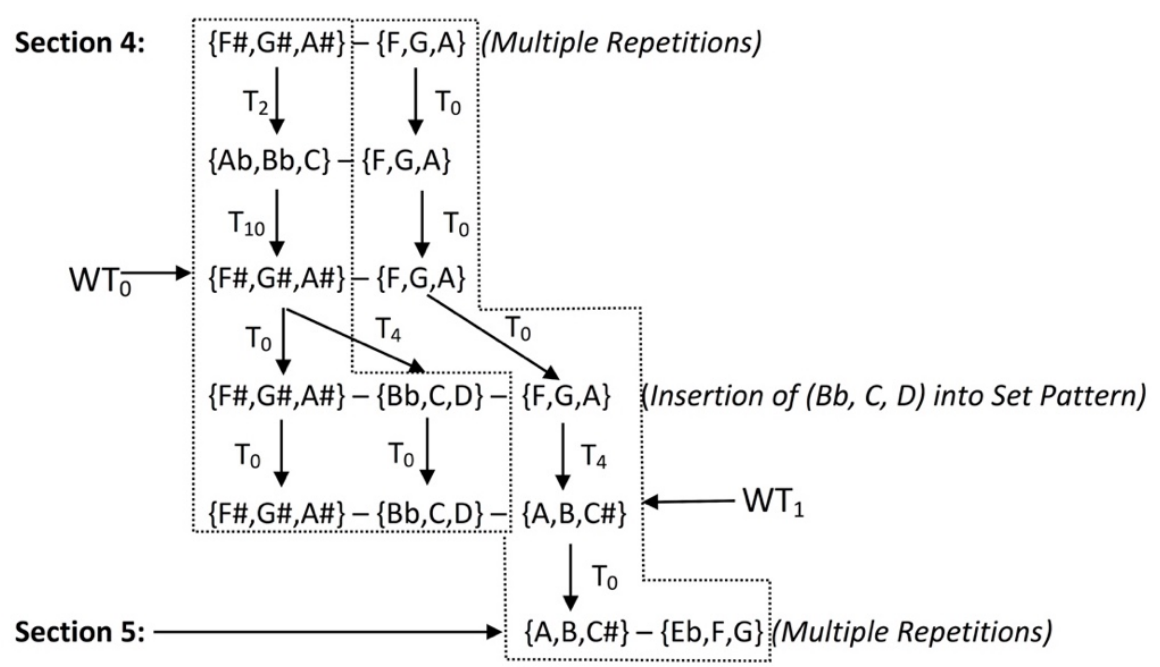

During the transition to Section 5, the emergence of a $\mathrm{WT}_{0}$ stream (Figure 22) results from the common-tone transpositions which occur. Whole-tone saturation is fully realized in Section 5 with $\{A, B, C \#\}$ and $\{E b, F, G\}$ forming a $W T_{1}$ collection. Throughout Sections 5 and $6, W_{1}$ is the primary superset for the trichords that appear. $\{E b, F, G\}$ is occasionally fragmented during Section 5 , eventually emerging as a referential set during the transition to Section 6 where it is repeated and then contrasted with five other $T_{n}$-related members of $(0,2,4)$. In Section 6 , Coltrane alternates between $\{E b, F, G\}$ and $\{D b, E b, F\}$ in different octaves, sometimes blending them 
together forming $\{D b, E b, F, G\}$. In the transition to Section 7, the $T_{3}$-related sets $\{C, D, E\}$ and $\{E b, F, G\}$ chromatically anticipate Section 7 and the two $T_{3} / T_{9}$ related sets $\{B, C \#, D \#\}$ and $\{D, E, F \#$. The use of $(0,2,4)$ as a structural determinant ends with these two trichords.

\section{SUPERSETS AND SLONIMSKY COMPARISONS}

While the preceding analysis illustrates the structural relationships between Sections 3 and 7 , an investigation of Sections 1 and 2 will consider the significance of the pc sets within the context of supersets and Slonimsky's Thesaurus of Scales and Melodic Patterns.

Coltrane's improvisation begins in Section 1 with the introduction and repetition of $\{F \#, G \#, A \#\}$. This trichord emerges from the melodic development of the G\# minor pentatonic scale which precedes it and the C\# minor tonality established by the "Saturn" theme. The introduction of $\{B, C \#, D \#\}$ is anticipated by Coltrane with the interjection of a single $B$ within the motivic development of $\{\mathrm{F} \#, \mathrm{G} \#, \mathrm{A \#}\}$. This type of anticipation is also found at several other points during Coltrane's improvisation. While the $T_{5} / T_{7}$ related pc sets $\{F \#, G \#, A \#\}$ and $\{B, C \#, D \#\}$ maintain a tonal connection to the "Saturn" theme as subsets of C\# minor (Dorian), Coltrane also mimics the theme's melodic architecture by ending his phrases on pitches G\# and C\#. At first Coltrane repeats $\{F \#, G \#, A \#\}$ and $\{B, C \#, D \#\}$ twice - preserving their distinctiveness - before blending them into one seamless $(0,2,4,5,7,9)$ hexachordal structure (Figure 23 ). 
Figure 23. "Saturn" Section 1 synthesis of two trichords (03:20).

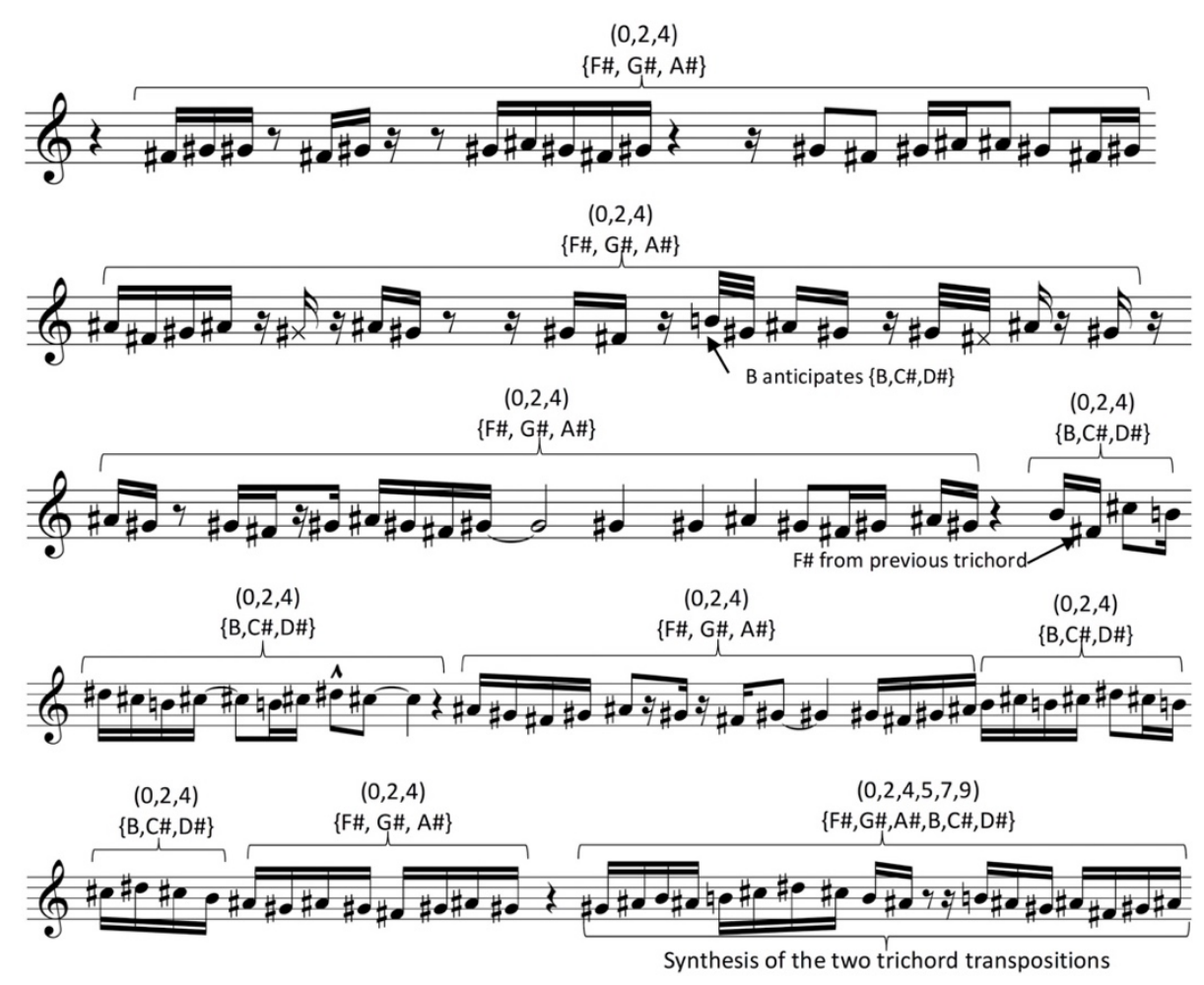

Closely related to this example, two pairs of T7-related $(0,2,4)$ sets in "Saturn" occur later in the improvisation (8:11). In this instance, the four pc sets $-\{G, A, B\},\{D, E, F \#\},\{D b, E b, F\},\{A b, B b, C\}-$ form a twelve-tone aggregate (Figure 24). The interjection of dyads $\{\mathrm{Ab}, \mathrm{Bb}\}$ and $\{\mathrm{Db}, \mathrm{Eb}\}$ as fragments of $\{\mathrm{Ab}, \mathrm{Bb}, \mathrm{C}\}$ and $\{\mathrm{Db}, \mathrm{Eb}, \mathrm{F}\}$ delays the complete statement of the last $\mathrm{pc}$ set in the series $\{\mathrm{Ab}, \mathrm{Bb}, \mathrm{C}\}$. Exercise \#1293 in Slonimsky's Thesaurus (Figure 25) shares a strikingly similar construction to Figure 24. 
Figure 24 . Four $(0,2,4)$ pitch-class sets forming a twelve-tone aggregate $(08: 11)$.

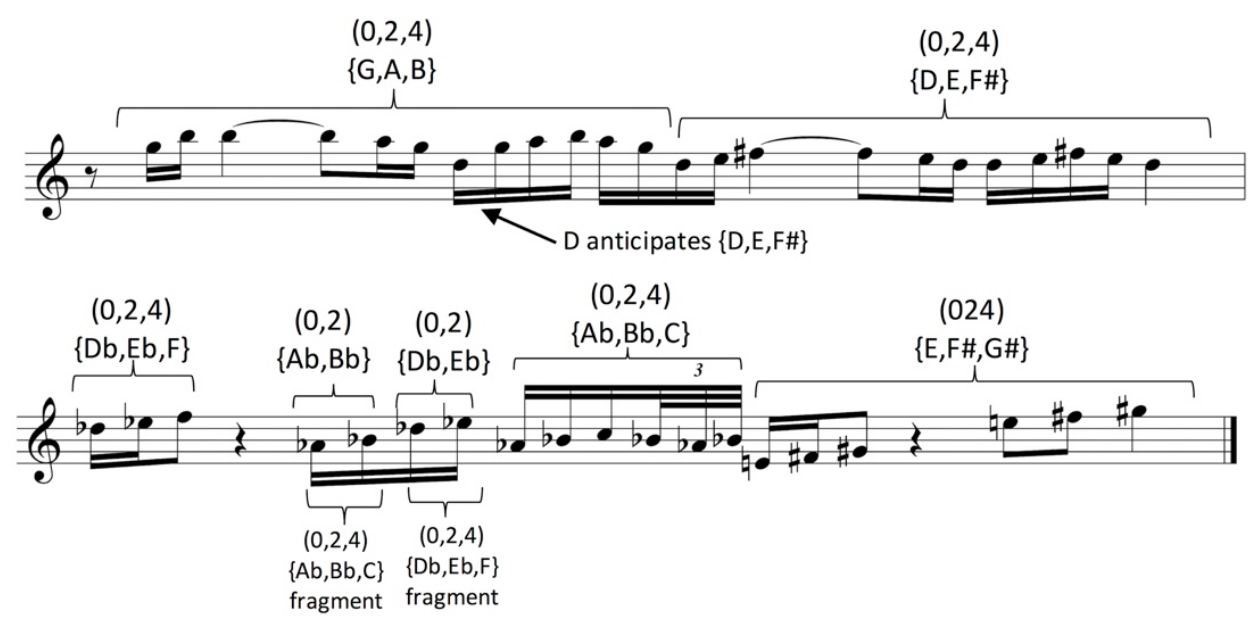

Figure 25. The structural model for Slonimsky's Exercise \#1293.

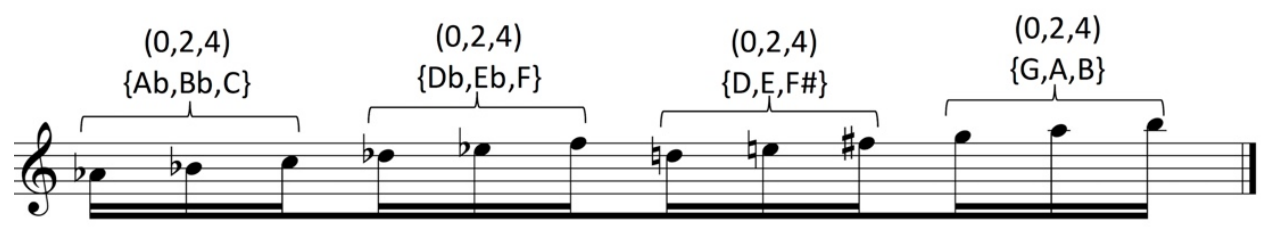

Section 2 begins with the introduction of $\{C, D, E\}$, mapping from $\{B, C \#, D \#\}$ at $T_{1}$. In contrast to Section 5, which also contains $T_{6}$ related sets, here $\{F \#, G \#, A \#\}$ and $\{C, D, E\}$ are embellished with pitches $\mathrm{F}$ and $\mathrm{B}$ (Figure 26). This transforms these tritone-related sets (a $\mathrm{WT}_{0}$ collection) into the symmetrical collection $(0,1,2,4,6,7,8, T)$. Significantly, this collection is found as Scale \#21 in Slonimsky's Thesaurus while also known more widely as Olivier Messiaen's sixth mode of limited transposition (Figure 27)..$^{15}$

\footnotetext{
${ }^{15}$ During an interview with J.C. Dargenpierre in 1961 (DeVito 2012, 127), Coltrane mentions reading the book Since Debussy (Hodeir 1961). This book contains a chapter on Olivier Messiaen that describes his compositional techniques and the "modal power" of the modes of limited transposition, suggesting their potential relationship to Greek, Chinese and Hindu modes (112). Hodeir also makes reference to Messiaen's book, The Technique of My Musical Language (1956) where the modes of limited transposition also appear.
} 
Figure 26 . $T_{6}$ related $(0,2,4)$ members with added pitch-classes $F$ and $B(03: 40)$.
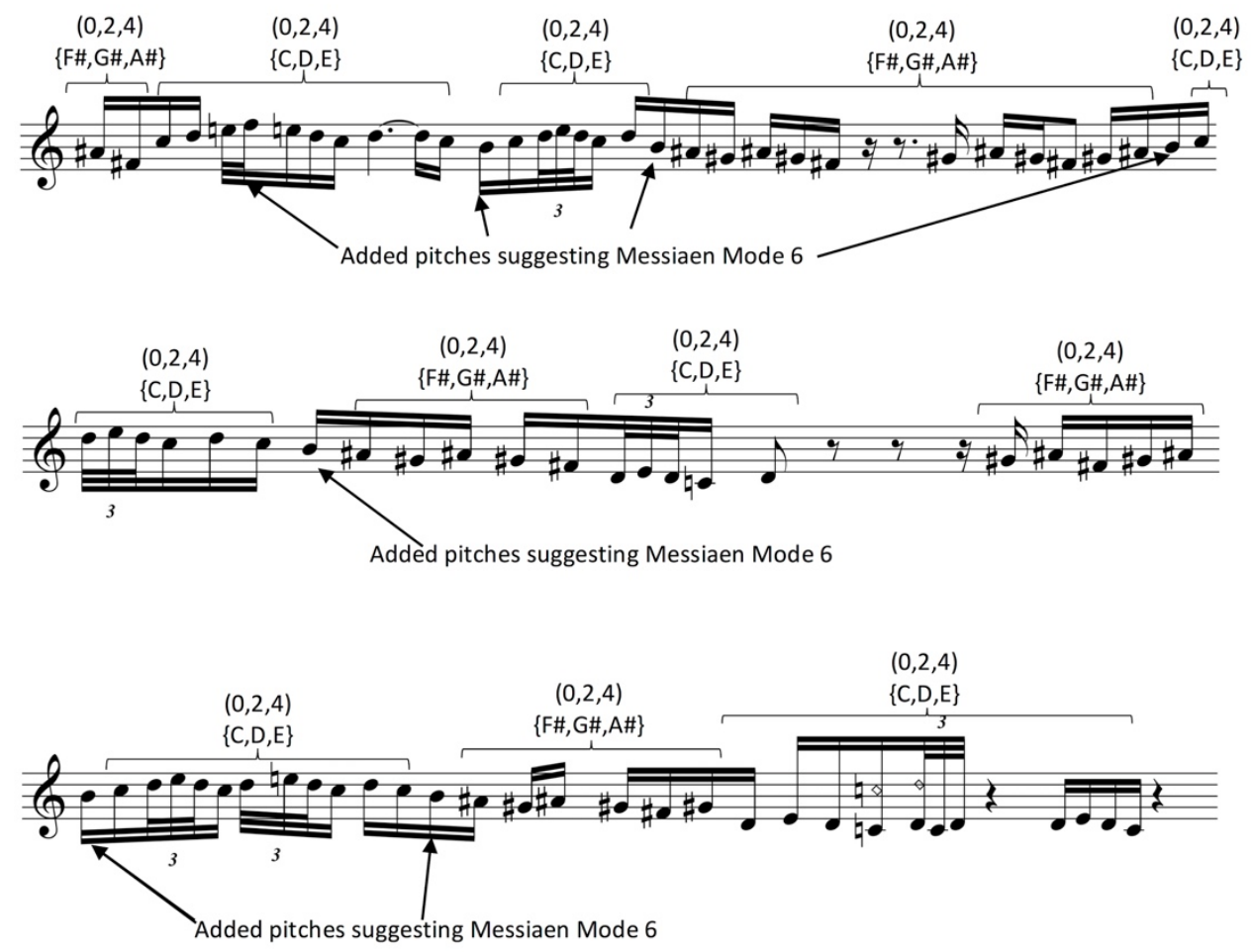

Figure 27. The structural model for Slonimsky’s Scale \#21 and Messiaen Mode 6.

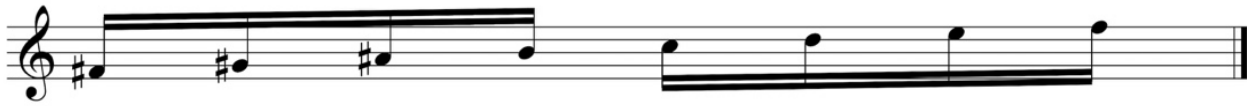

During the development of Section 2 there is a brief interruption in the structural continuity of $(0,2,4)$ and the superset $(0,1,2,4,6,7,8, T)$. This divergence begins with a sweeping ascending line that reaches into the altissimo register and then descends. The registral limits of this line are then developed, contrasting the extreme altissimo with the low register of the saxophone. This is followed by a brief transition using subsets of $\mathrm{WT}_{0}$ and a return to the $(0,2,4)$ structure. Throughout this section the $W_{0}$ subsets $\{F \#, A \#, C\},\{A \#, C, D, F \#\}$, and $\{F \#, G \#, A \#, D\}$ interact with the more chromatic pitch content, providing continuity in the whole-tone sonority while framing the sweeping ascending line and the entire section (Figure 28). The pitch-classes F\# and A\#, as 
members of $\{F \#, A \#, C\},\{A \#, C, D, F \#\}$, and $\{F \#, G \#, A \#, D\}$, maintain a connection to the referential set $\{F \#, G \#, A \#\}$ which re-emerges after this divergence.

Figure 28. "Saturn" $(0,2,4)$ divergence and $\mathrm{WT}_{0}$ subset interactions (03:51).

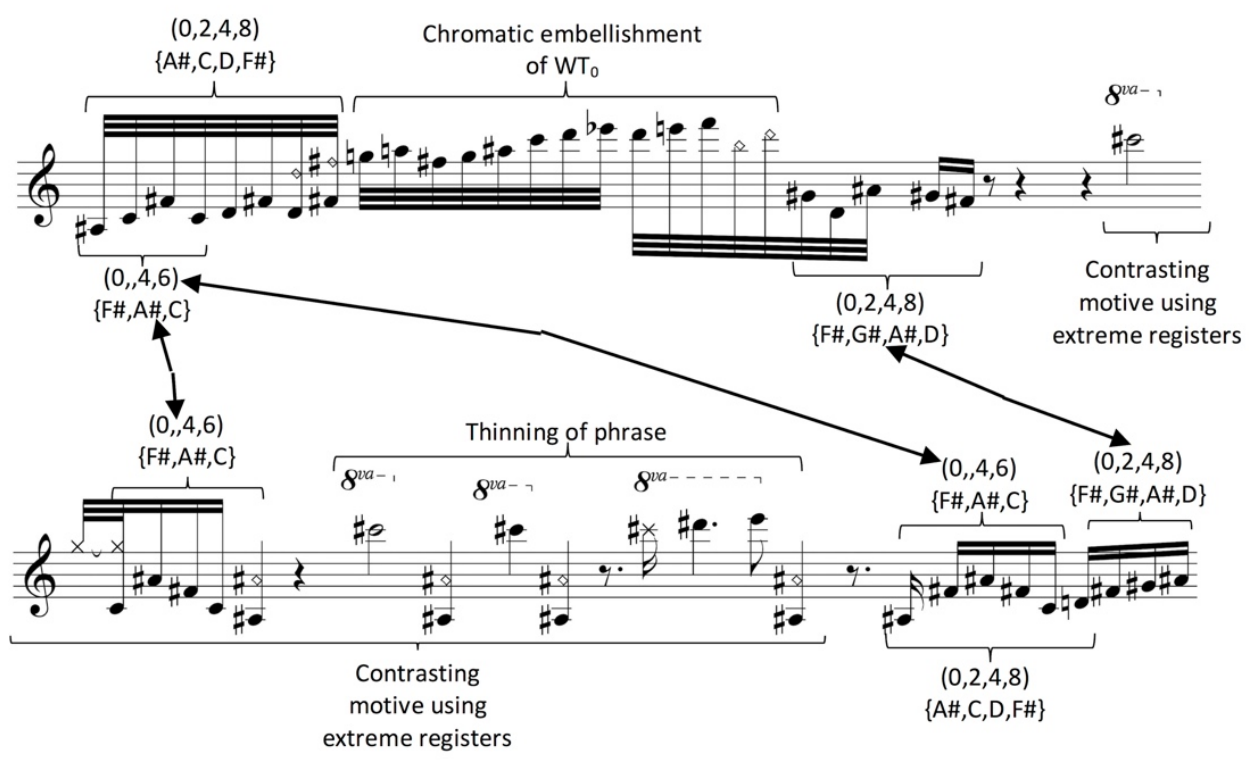

This section of Saturn demonstrates Coltrane's extraordinary skill at using the members of $(0,2,4)$ in a variety of ways. These trichordal explorations engage with the functional harmony displayed in the theme, symmetrical supersets, and twelve-tone sequences while also using pairs of trichords to establish harmonic regions that combine to form a larger narrative. Significant parallels occur between the content of Coltrane's improvisations and the theoretical concepts of Messiaen and Slonimsky. Case Study C presents further evidence of these connections and their potential links to Coltrane's earlier music.

\section{CASE STUDY C - “SATURN" ANALYSIS 2}

In this final case study, a second investigation of "Saturn" demonstrates evidence of $T_{n}$-type $(0,2,5)$ as the structural generator of the melodic content starting at 6:43. The musical narrative here develops in a different manner from what has been seen in the previous two case studies, using primarily two overlapping interval cycles - C2 (whole tone) and C5 (perfect fourths/fifths) 
- for the $T_{n}$ operations between members of $(0,2,5) .{ }^{16}$ This $T_{n}$-type has additional harmonic significance due to its two occurrences as subsets within the blues and pentatonic scales.

In this section, an interesting relationship emerges in regard to $(0,2,5)$ and its inversion, $(0,3,5)$ - widely known as the principal structure in "Acknowledgment" from A Love Supreme (Figure 29). ${ }^{17}$

Figure 29. A Love Supreme motive.

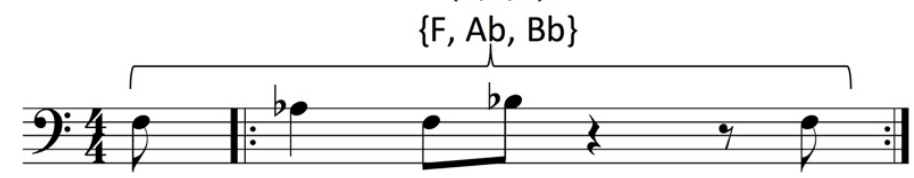

Coltrane begins this section of "Saturn" (Figure 30) as if it had been extracted from "Acknowledgement" (Figure 31), substituting members of $(0,2,5)$ for members of $(0,3,5)$, while using a segment of the $\mathrm{C} 5$ cycle as the transposition operation for the pc sets. This construction occurs in Slonimsky's Thesaurus as Exercise \#827, with nested members of $(0,2,5)$ and $(0,3,5)$ clearly observed within the C5 pattern (Figure 32). ${ }^{18}$ Additionally, a series of overlapping pentatonic scales exists within Exercise \#827.

\footnotetext{
${ }^{16}$ For more on transposition cycles see Lambert $(1997,128)$.

${ }^{17}$ Porter's analysis of $A$ Love Supreme identifies the main motive as 'Cell $a^{\prime}$ ' $(1998,234)$-a member of $(0,3,5)$-while in Free Jazz $(1974,88)$ Jost notes the connection between the main motive of $A$ Love Supreme and Ascension (1966).

${ }^{18}$ Bair (2003) also identifies perfect-fourth (61) and major-second interval-cycles (83) within this section of "Saturn," similarly observing a correspondence to \#827, and is strictly focused on using Slonimsky's vocabulary as the means for his interpretation. My analysis differs from Bair's by arguing that $(0,2,5)$ is the salient feature of this section. This interpretation provides a broader understanding of the pitch content-independent of its cyclical constructions-and demonstrates an organizational connection between the use of $(0,2,5)$ as a structural determinant in "Saturn", and the use of $(0,1,3)$ and $(0,2,4)$ as structural determinants in Case Studies A and B, where numerous non-cyclical $T_{n}$ operations occur between trichords. Furthermore, this interpretation allows for the illustration of inversional relationships between (035) and (025), as shown in Figures 30 and 31.
} 
Figure 30. "Saturn" $(0,2,5)$ members within a C5 cycle (06:43).

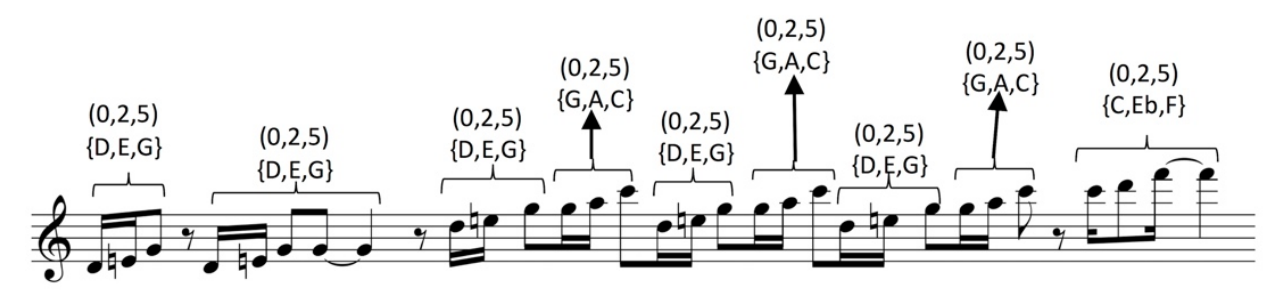

Figure 31. "Acknowledgement" $(0,3,5)$ members within a C5 cycle $(02: 05)$.

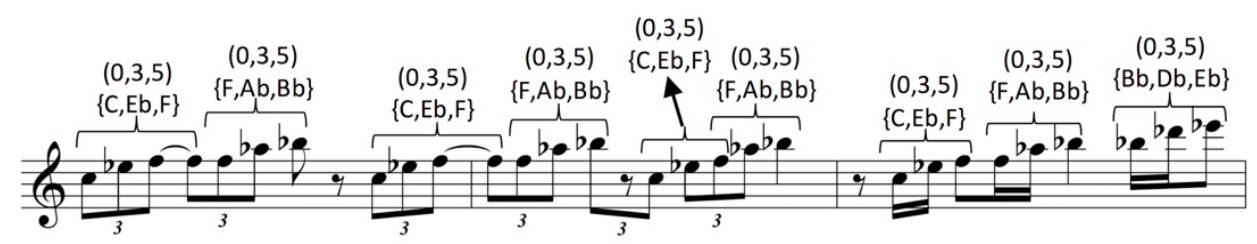

Figure 32. The structural model for Slonimsky’s Exercise \#827.

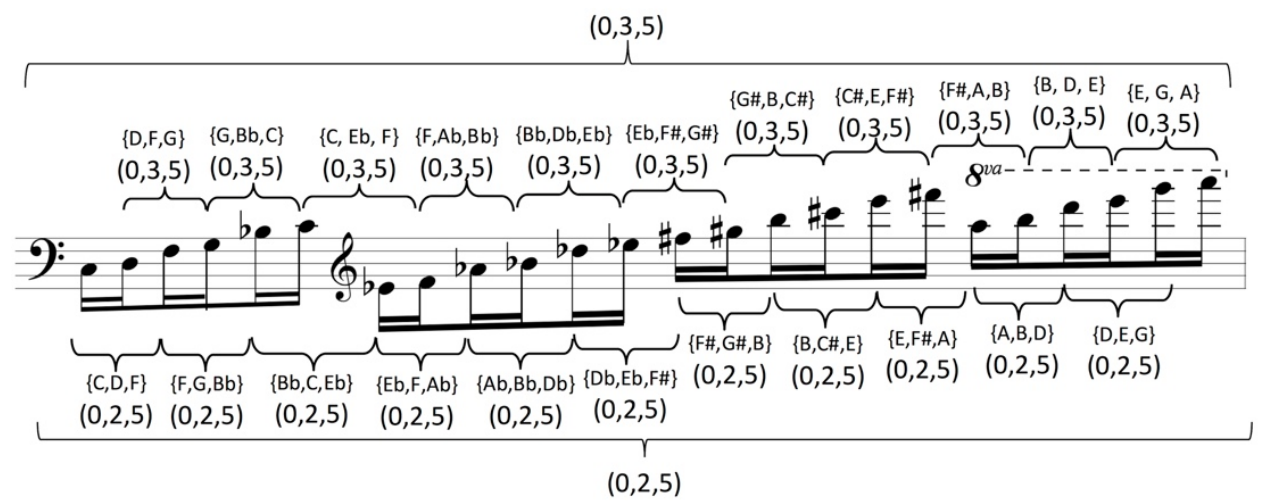

A closer examination of the C2 and C5 cycles contained in "Saturn" reveals three instances where trichords are used to pivot between these transpositional cycles (Figure 33). During this section, $\mathrm{C} 2_{1}$ is the only interval cycle that sounds completely, while smaller segments of the $\mathrm{C} 2_{0}$ and $\mathrm{C} 5$ cycles also appear. Significantly, there are three disruptions to these cycles. The first occurs with the insertion of $\{A b, B b, D b\}$ between the previously repeated two-trichord pattern $\{C, D, F\}$ and $\{G, A, C\}$. In the second disruption a chromatic pc set substitution appears within the C5 cycle. Here, $\{B b, C, E b\}$ replaces $\{B, C \#, E\}$ during what otherwise would be a sequence of six $T_{5}$-related sets starting with $\{\mathrm{Ab}, \mathrm{Bb}, \mathrm{Db}\}$. In the final disruption there is a denial of the expected trichord 
$\{G, A, C\}$ within this $C 2_{1}$ cycle because of an alteration in this set's pitch-class content (F\# replacing G). The resulting $p c$ set $\{F \#, A, C\}-$ a member of $(0,3,6)$ - is immediately followed by $\{F, G, B b\}$, returning to the $\mathrm{C} 2_{1}$ cycle and members of $(0,2,5)$.

Figure 33. "Saturn" $(0,2,5)$ transpositional sequence $(6: 43-7: 14)$.

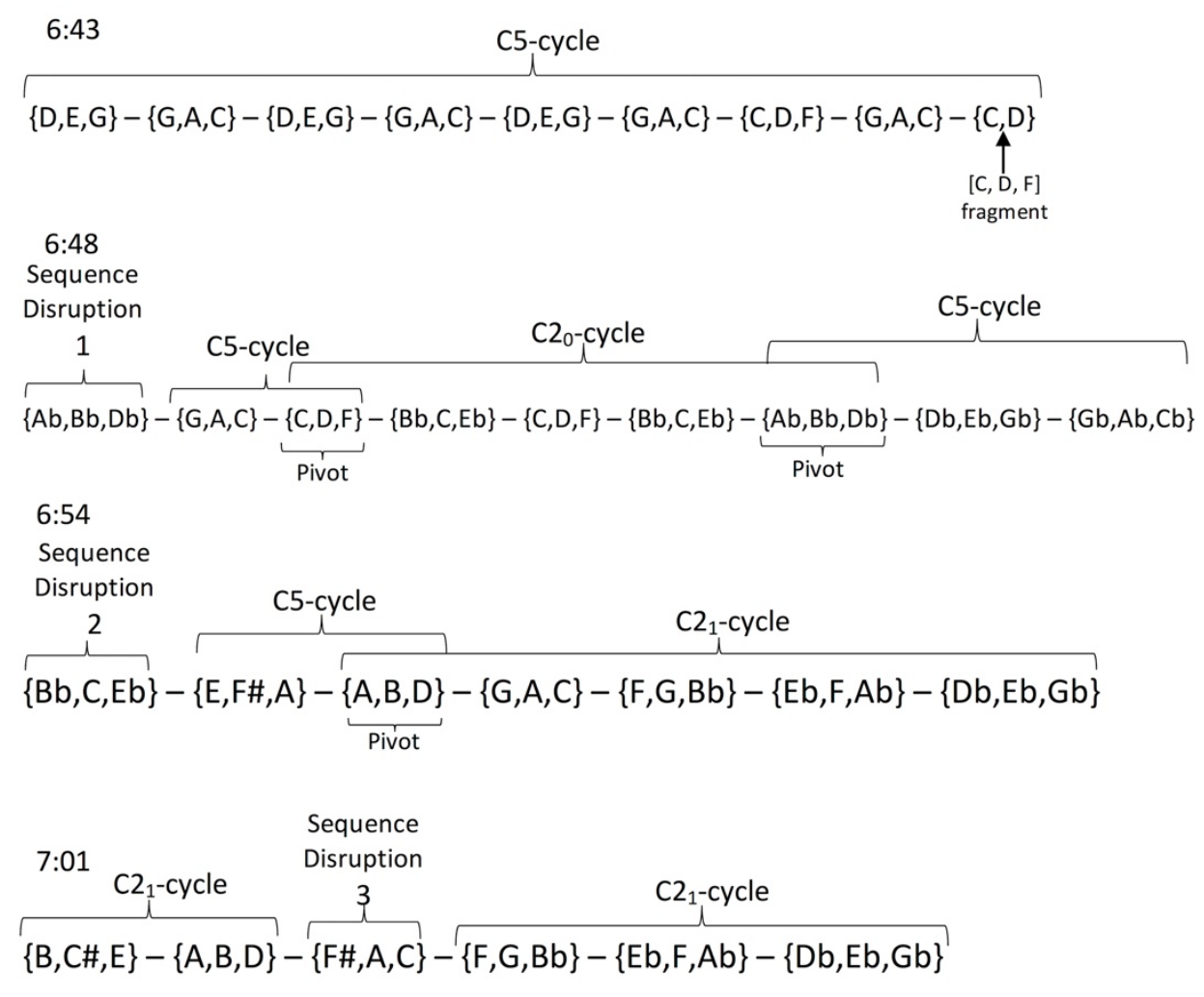

$\overbrace{\{B, C \#, E\}-\{D b, E b, G b\}-\{E b, F, A b\}-\{F, G, B b\}-\{G, A, C\}-\{A, B, D\}}^{C 2_{1}-\text { cycle }}$

Coltrane ends this section with a transition that contains several structural characteristics (Figure 34). The first and most obvious feature is the tonal reference to an authentic cadence in A minor. Secondly, $\{E, F \#, B\}$, as a member of $(0,2,7)$, is a whole step expansion of $(0,2,5)$ that reproduces the preceding melodic contour. Additionally, $\{E, F \#, B\}$ anticipates the extended exploration of members of $(0,2,7)$ that immediately follows this section. A third interpretation offers another 
connection to the $(0,2,5)$ structure with the prolongation of $\{E, F \#, A\}$, embellished by tones $B$ and G\# which both resolve to $A$. Lastly, the harmonic shift from tetrachords $\{A, B, D, E\}$ to $\{G, A, C, D\}$ suggests the movement from $B$ minor pentatonic to A minor pentatonic, demonstrating another connection to Exercise \#827, and the overlapping pentatonic scales it contains.

Figure 34. Ending transition from $(0,2,5)$ section to $(0,2,7)$ section $(07: 08-07: 14)$.

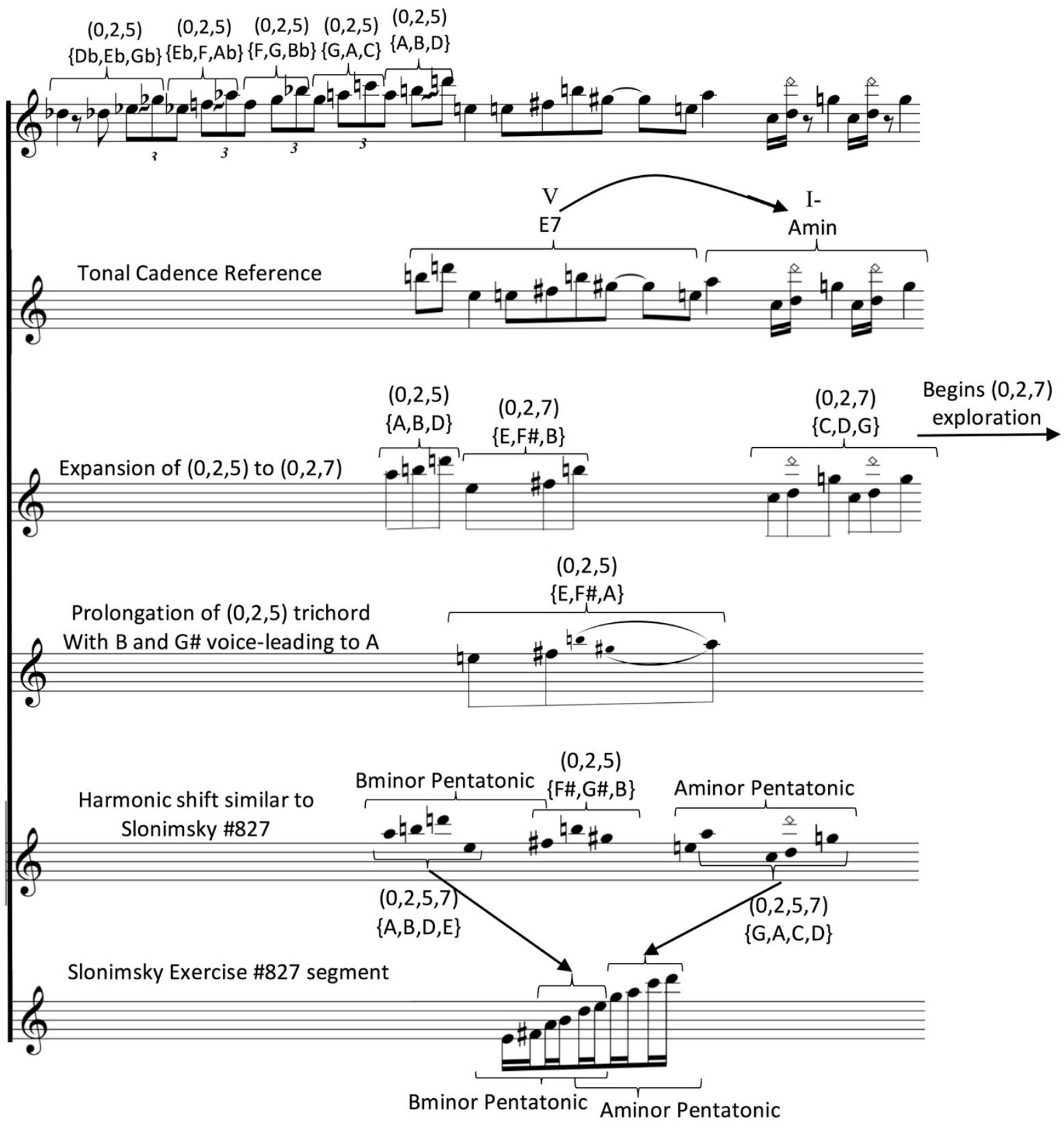




\section{CONCLUSION}

These three case studies present substantial evidence that Coltrane's improvisations are highly structured, displaying an organizational design where motives are constructed from trichords belonging to specific $T_{n}$-types. The melodic narratives presented in the analyses demonstrate remarkable trichordal consistency, focused especially around $(0,1,3),(0,2,4)$ and $(0,2,5)$. While each case study has unique elements, together they reveal a larger pattern in Coltrane's improvisations where interval content is a unifying force and where trichordal pitch-class sets realize this interval content with clarity and melodic precision. The manner in which Coltrane treats the members of these three $T_{n}$-types indicates a deep understanding of their melodic potential and their relationships to larger collections, twelve-tone aggregates, and tonal harmony. Significant parallels to the theoretical constructions of Slonimsky and Messiaen can be found in these improvisations, as represented by a variety of cyclical patterns and symmetric constructions.

As an archetype for an improvisational approach encompassing both motive and harmony, "Iris" has significance that resonates throughout Stellar Regions, Interstellar Space, and to Coltrane's late-period work more generally. The structural content of "Iris" demonstrates that this lateperiod work should not be regarded as chaotic or disorganized, but rather as some of the most organized music Coltrane ever created.

\section{REFERENCES}

Bair, Jeff. 2003. “Cyclic Patterns in John Coltrane's Melodic Vocabulary as Influenced by Nicolas Slonimsky's 'Thesaurus of Scales and Melodic Patterns': An Analysis of Selected Improvisations." D.M.A. diss., University of North Texas.

Bauer, Bob and Chuck Sher, eds. 1991. The New Real Book: Volume Two. Petaluma, California: Sher Music. 
Block, Steven. 1990. "Pitch-Class Transformation in Free Jazz." Music Theory Spectrum 12/2: 181-202.

Berkman, David. 2013. The Jazz Harmony Book. Petaluma, California: Sher Music.

Brown, Leonard, ed. 2010. John Coltrane and Black America's Quest for Freedom: Spirituality and the Music. New York: Oxford University Press.

Clements, Carl. 2008. "John Coltrane and the Integration of Indian Concepts in Jazz Improvisation." Jazz Research Journal 2/2: 155-175.

Cole, Bill. 1976. John Coltrane. New York: Da Capo Press.

Crouch, Stanley. 2006. Considering Genius: Writings on Music. New York: Basic Civitas Books.

DeVito, Chris. 2012. Coltrane on Coltrane: The John Coltrane Interviews. Chicago: Chicago Review Press.

DeVito, Chris, Yasuhiro Fujioka, Wolf Schmaler, David Wild, and Lewis Porter. 2013. The John Coltrane Reference. Edited by Lewis Porter. London: Routledge.

Dibben, Nicola. 1999. "The Perception of Structural Stability in Atonal Music: The Influence of Salience, Stability, Horizontal Motion, Pitch Commonality, and Dissonance."Music Perception: An Interdisciplinary Journal 16/3: 265-294.

Dyer, Geoff. 2014. "Catastrophic Coltrane. The New York Review of Books." Oct. 14. Available at: (http://www.nybooks.com/daily/2014/10/04/catastrophic-coltrane/).

Forte, Allen. 1973. The Structure of Atonal Music. New Haven: Yale University Press.

- 1988. "New Approaches to the Linear Analysis of Music." Journal of the American Musicological Society 41/2: 315-348.

Hall, James. 2001. Mercy, Mercy Me. Oxford: Oxford University Press.

Hodeir, Andre. 1961. Since Debussy: A View of Contemporary Music. London: Secker \& Warburg.

Howison, Jamie. 2012. God's Mind in That Music: Theological Explorations Through the Music of John Coltrane. Eugene: Cascade Books.

Jost, Ekkehard. 1974. Free Jazz. Reprint, New York: Da Capo Press, 1994. 
Kahn, Ashley. 2003. A Love Supreme: The Story of John Coltrane's Signature Album. New York: Penguin.

Kofsky, Frank. 1998. John Coltrane and the Jazz Revolution of the 1960s. 2nd edition. New York: Pathfinder Books.

Lambert, Phillip. 1997. The Music of Charles Ives. New Haven: Yale University Press.

Liebman, David. 1996. "Coltrane's Meditations Suite: A Study in Symmetry." Annual Review of Jazz Studies 8: 167-180.

McGill, Scott. 2014. “Arnold Schoenberg, Dennis Sandole, and John Coltrane: Important Links in Modern Jazz Pedagogy and Practice." [online]. Available at: (https://www.academia.edu/27068692/Arnold_Schönberg_Dennis_Sandole_and_John_ Coltrane_Important_Links_in_Modern_Jazz_Pedagogy_and_Practice).

McMullan, Gordon and Sam Smiles, eds. 2016. Late Style and Its Discontents: Essays in Art, Literature, and Music. Oxford: Oxford University Press.

Medwin, Marc. 2008a. "Attaining Unity: Self-Reference in the Music of John Coltrane." Jazz Research Journal 2/2: 119-131.

- 2008b. "Listening in Double Time: Temporal Disunity and Structural Unity in the Music of John Coltrane 1965-1967." Ph.D. diss., The University of North Carolina at Chapel Hill.

Messiaen, Olivier. 1956. The Technique of My Musical Language. Reprint, Paris: A. Leduc, 2007.

Nisenson, Eric. 1995. Ascension: John Coltrane and His Quest. New York: Da Capo Press.

O'Gallagher, John. 2016. Transcriptions of "Iris" and "Saturn": Unpublished.

Porter, Lewis. 1998. John Coltrane: His Life and Music. 5th edition. Ann Arbor: The University of Michigan Press.

Pressing, Jeff. 1982. "Pitch Class Set Structures in Contemporary Jazz." Jazzforschung 14: 133172.

Rahn, John. 1980. Basic Atonal Theory. New York: Schirmer Books.

Ratliff, Ben. 2008. Coltrane: The Story of a Sound. London: Faber \& Faber.

Schott, John. 2000. "We Are Revealing a Hand That Will Later Reveal Us: Notes on Form and Harmony in Coltrane's Work." In Arcana: Musicians on Music, edited by John Zorn, 345368. 3rd edition. New York: Granary Books. 
Simpkins, Cuthbert. 1975. Coltrane: A Biography. Baltimore: Black Classic Press.

Slonimsky, Nicolas. 1947. Thesaurus of Scales and Melodic Patterns. New York: Scribner.

Smith, Martin. 2001. John Coltrane: Jazz, Racism and Resistance. London: Redwords.

Solomon, Larry. 1982. "The List of Chords, Their Properties and Use in Analysis." Interface 11/2: 61-107.

_ 1998. "Set Theory Primer for Music. Solomon's Music Resources." Available at: (http://solomonsmusic.net/setheory).

_ 2005. "The Table of Pitch Class Sets. Solomon's Music Resources." Available at: (http://solomonsmusic.net/pcsets).

Straus, Joseph. 2000. Introduction to Post-Tonal Theory. $2^{\text {nd }}$ Edition. Englewood Cliffs: Prentice Hall.

Thomas, J.C. 1976. Chasin' the Trane: The Music and Mystique of John Coltrane. New York: Da Capo Press.

Voss, Dan. 2014. "Problems of Harmonic Interpretation in Late Coltrane. Music BlogÜbergreifen." April 23. Available at:

(http://uebergreifen.blogspot.co.uk/2014/04/problems-of-harmonic-interpretationin.html).

—. 2015. "Venus. Music Blog-Übergreifen." May 22. Available at: (http://uebergreifen.blogspot.co.uk/2015/05/).

Whyton, Tony. 2013. Beyond a Love Supreme: John Coltrane and the Legacy of an Album. New York: Oxford University Press.

Woideck, Carl. 1998. The John Coltrane Companion. New York: Schirmer.

\section{DISCOGRAPHY}

Coltrane, John. 1965. A Love Supreme. Englewood Cliffs, NJ: Impulse A-77.

—. 1965. posthumous release 1971. Live in Seattle. Seattle, WA: Impulse AS-9202-2.

—. 1966. Ascension. Englewood Cliffs, NJ: Impulse A-95. 
—. 1967. Expression. Englewood Cliffs, NJ: Impulse A-9120.

- 1967. posthumous release 1974. Interstellar Space. Englewood Cliffs, NJ: Impulse ASD9277 [LP]. 2000 release. Impulse-314 543 415-2 [CD].

—. 1967. posthumous release 1995. Stellar Regions. Englewood Cliffs, NJ: Impulse IMP-169. 